\title{
Melatonin in Mitochondrial Dysfunction and Related Disorders
}

\author{
Venkatramanujam Srinivasan, ${ }^{1}$ D. Warren Spence, ${ }^{2}$ Seithikurippu R. Pandi-Perumal, ${ }^{3}$ \\ Gregory M. Brown, ${ }^{4}$ and Daniel P. Cardinali ${ }^{5,6}$ \\ ${ }^{1}$ Sri Sathya Sai Medical, Educational and Research Foundation, Prashanthi Nilayam 40, \\ Kovai Thirunagar Coimbatore 641014, India \\ ${ }^{2} 323$ Brock Avenue, Toronto, ON, Canada M6K 2 M6 \\ ${ }^{3}$ Somnogen Inc., College Street, Toronto, ON, Canada M6H 1 C5 \\ ${ }^{4}$ Centre for Addiction and Mental Health, 250 College Street, Toronto, ON, Canada M5T 1R8 \\ ${ }^{5}$ Departamento de Docencia e Investigación, Facultad de Ciencias Médicas, Pontificia Universidad Católica Argentina, \\ Avenida Alicia Moreau de Justo 1500, $4^{\circ}$ Piso, 1107 Buenos Aires, Argentina \\ ${ }^{6}$ Departamento de Fisiologia, Facultad de Medicina, Universidad de Buenos Aires, 1121 Buenos Aires, Argentina
}

Correspondence should be addressed to Daniel P. Cardinali, danielcardinali@fibertel.com.ar

Received 28 November 2010; Accepted 2 March 2011

Academic Editor: B. J. Bacskai

Copyright ( 2011 Venkatramanujam Srinivasan et al. This is an open access article distributed under the Creative Commons Attribution License, which permits unrestricted use, distribution, and reproduction in any medium, provided the original work is properly cited.

\begin{abstract}
Mitochondrial dysfunction is considered one of the major causative factors in the aging process, ischemia/reperfusion (I/R), septic shock, and neurodegenerative disorders like Parkinson's disease (PD), Alzheimer's disease (AD), and Huntington's disease (HD). Increased free radical generation, enhanced mitochondrial inducible nitric oxide (NO) synthase activity, enhanced NO production, decreased respiratory complex activity, impaired electron transport system, and opening of mitochondrial permeability transition pore all have been suggested as factors responsible for impaired mitochondrial function. Melatonin, the major hormone of the pineal gland, also acts as an antioxidant and as a regulator of mitochondrial bioenergetic function. Both in vitro and in vivo, melatonin was effective for preventing oxidative stress/nitrosative stress-induced mitochondrial dysfunction seen in experimental models of $\mathrm{PD}, \mathrm{AD}$, and HD. In addition, melatonin is known to retard aging and to inhibit the lethal effects of septic shock or I/R lesions by maintaining respiratory complex activities, electron transport chain, and ATP production in mitochondria. Melatonin is selectively taken up by mitochondrial membranes, a function not shared by other antioxidants. Melatonin has thus emerged as a major potential therapeutic tool for treating neurodegenerative disorders such as $\mathrm{PD}$ or $\mathrm{AD}$, and for preventing the lethal effects of septic shock or I/R.
\end{abstract}

\section{Introduction}

Mitochondrial dysfunction is implicated in the etiology of various diseases, such as neurodegenerative diseases, diabetes, cardiovascular disease, various forms of hepatic disorders, skeletal muscle disorders, sepsis, and psychiatric disorders [1-10]. Abnormalities in mitochondrial functions such as defects in the electron transport chain (ETC)/oxidative phosphorylation (OXPHOS) system, Krebs's cycle enzymes, and ATP production have all been suggested as the primary causative factors in the pathogenesis of neurodegenerative disorders and sepsis.

Impaired mitochondrial dysfunction is regarded as the driving force for the ageing process [11]. Enhanced production of reactive oxygen species (ROS) and possibly accumulation of mitochondrial (mt) DNA mutations in postmitotic cells are considered to be contributory factors to age-related degeneration. Mitochondria not only generate ROS/reactive nitrogen species (RNS) but are also the main target of their actions [12]. As a result of this action, damage occurs in 
the mitochondrial respiratory chain, thus producing further increases in free radical generation, ultimately self-inducing a vicious cycle [13].

During the last decade, a number of studies have demonstrated that melatonin plays an effective role in regulating mitochondrial homeostasis. In addition to being a free radical scavenger, melatonin reduces nitric oxide (NO) generation within mitochondria. It maintains the electron flow, efficiency of oxidative phosphorylation, ATP production and bioenergetic function of the cell by regulating respiratory complex activities, $\mathrm{Ca}^{2+}$ influx, and mitochondrial permeability transition pore opening [14-18].

In this article, the several mechanisms through which melatonin exerts neuroprotective actions in neurodegenerative disorders such as Parkinson's disease (PD), Alzheimer's disease (AD), and Huntington's disease (HD) and in a number of mitochondrial dysfunction related conditions such as aging, ischemia/reperfusion (I/R), or septic shock, are reviewed. For another recent survey of literature see [19].

\section{Mitochondrial Function and Free Radical Generation}

Mitochondria contain multiple copies of a circular genome (chromosome) known as mtDNA as it has been characterized in humans [20]. Although the majority of mitochondrial proteins essential for normal bioenergetic function are encoded by nuclear DNA [21], some proteins needed for ETC/OXPHOS are encoded by mtDNA. Human mitochondrial genome encodes for 13 peptides of subunits of complexes I, III, and IV, and ATP synthase complex, 22 transfer RNAs and 2 ribosomal nucleic acids, while nuclear DNA encodes for at least 1000 mitochondrial proteins [22].

The primary function of mitochondria is to generate ATP within the cell through the ETC resulting in OXPHOS. The ETC, which is present in the inner mitochondrial membrane, comprises a series of electron carriers grouped into four enzyme complexes, namely, complex I (NADH ubiquinone reductase), complex II (succinate ubiquinone reductase), complex III (ubiquinol cytochrome-c-reductase), and complex IV (cytochrome c oxidase) [23].

The main function of the ETC is to convert redox energy into an electrochemical gradient of protons that subsequently causes ATP formation from ADP and phosphate by ATP synthase. The end product of the respiratory chain is water that is generated in a four-electron reduction of molecular oxygen $\left(\mathrm{O}_{2}\right)$ by complex IV. During this process (electron leakage especially at complex I and III), a small percentage of $\mathrm{O}_{2}$ is converted into ROS, such as superoxide anion radical $\left(\mathrm{O}_{2}{ }^{\bullet-}\right)$ and its secondary products hydrogen peroxide $\left(\mathrm{H}_{2} \mathrm{O}_{2}\right)$ and reactive hydroxyl radical $(\bullet \mathrm{OH})[23$, 24]. Under normal conditions, the iron-sulfur cluster $\mathrm{N}_{2}$ of complex I appears to be the primary source of free radicals in the brain $[23,25]$.

Mitochondrial NO synthase (mtNOS) localized in the inner mitochondrial membrane is responsible for generating $\mathrm{NO}$ radical $\left({ }^{\bullet} \mathrm{NO}\right)$ from L-arginine [26]. Localization of mtNOS refers only to myristoylated nNOS splice variant alpha, which is also relevant because of its interaction with Complex IV. Because of NO diffusion, cytoplasmic NOS forms are also relevant for generating ${ }^{\circ} \mathrm{NO}$. High rates of ${ }^{-N O}$ synthesis, which typically occur in the calciumdependent excited state of neurons, can contribute to oxidative and nitrosative stress. The availability of $\bullet \mathrm{NO}$ determines the rates at which the adduct peroxynitrite $\left(\mathrm{ONOO}^{-}\right)$and the decomposition products are generated.

The free radical ${ }^{-} \mathrm{NO}$ is produced by several forms of NOS. In the mitochondria, two NOS isoforms, namely constitutive and inducible have been reported (c-mtNOS and $\mathrm{i}$-mtNOS). Since ${ }^{\circ} \mathrm{NO}$ is an uncharged gaseous compound, it crosses membranes with ease and can enter mitochondria regardless of their neuronal, glial, or vascular origin. ${ }^{\circ} \mathrm{NO}$ strongly interferes with components of the respiratory chain, in particular cytochrome C oxidase [27-29]. Its metabolite $\mathrm{ONOO}^{-}$and radicals derived from this can damage proteins of respiratory complexes. Other nitrosation processes, like transnitrosation or reversible nitrosation and nitration as well as irreversible protein and lipid oxidation, can occur.

Upon entering neuronal mitochondria, ${ }^{\circ} \mathrm{NO}$, in combination with $\mathrm{ONOO}^{-}$(formed there by combination with $\mathrm{O}_{2}{ }^{--}$from electron leakage), not only interferes with respiratory chain complexes but, when it reaches elevated levels, can trigger free radical-mediated chain reactions that in turn destroy protein, lipid, and DNA molecules [30-32]. As it has been stated above, damage to the mitochondrial respiratory chain can cause a breakdown of the proton potential, apoptosis, or lead to further generation of free radicals, thus maintaining a vicious cycle that ultimately results in cell death $[23,33]$.

In the mitochondrial-mediated cell death pathway, a nonspecific increase in the permeability of the inner mitochondrial membrane occurs, when mitochondrial matrix calcium is greatly increased [34]. This is known as mitochondrial permeability transition (mtPT), a process associated with the opening of channels in the inner mitochondrial membrane, which in turn causes a flux of molecules of $<1500$ daltons [35].

Both $\mathrm{Ca}^{2+}$ and ROS are major mtPT regulators. The inner mitochondrial membrane possesses a uniporter to transport $\mathrm{Ca}^{2+}$ into the matrix. With $\mathrm{Ca}^{2+}$ overload, there is complete uniporter inhibition, mitochondrial swelling, loss of respiratory control, and a release of matrix calcium caused by mtPT pore opening $[35,36]$. Under these conditions, ATP is hydrolyzed by mitochondria, the mitochondria undergo swelling, and mitochondrial-mediated apoptosis occurs.

Free radicals are continually generated in cells during normal activity. This process is essential for normal cellular physiology [37]. A number of mechanisms take part in the control of ROS/RNS production. Among these is the action of the enzyme superoxide dismutase (SOD), which occurs in the inner side of the inner mitochondrial membrane (MnSOD), that remove $\mathrm{O}_{2}{ }^{\bullet-}$ [38]. ${ }^{\bullet} \mathrm{OH}$ generated from $\mathrm{H}_{2} \mathrm{O}_{2}$ in the presence of reduced transition metals are scavenged by the enzyme glutathione peroxidase (GPx), during the process of metabolism of reduced glutathione (GSH) to its disulfide (GSSG), which in turn is reduced back to GSH by the enzyme glutathione reductase (GRd) [39]. 
These enzymes form part of the endogenous antioxidant defense system and suppress ROS levels within the cell as well as within the mitochondria. Antioxidants such as ascorbate, ubiquinone, or $\alpha$-tocopherol can participate in the mitochondrial antioxidative defense system, but none of them can convert $\mathrm{O}_{2}{ }^{\cdot-}$ to $\mathrm{O}_{2}$. It is GSH that participates in scavenging $\mathrm{O}_{2}{ }^{--}$, as well as in several redox reactions and maintains the mtTP pore closed. The redox cycling in the mitochondria is very active and serves to prevent significant loss of GSH. This is important because the mitochondria contain GPx and GRd activities and depend only on GSH uptake from the cytoplasm to keep adequate GSH levels.

Since melatonin promotes de novo synthesis of GSH by stimulating the activity of the enzyme $\gamma$-glutamylcysteine synthetase [40] and also through its effects on gene expression of GPx, GRd, SOD, and CAT [41-45] helping in the recycling of GSH and in maintaining high GSH/GSSG ratio [46], the role it plays in mitochondrial physiology is important [47].

\section{Melatonin: Biosynthesis, Metabolism, and Receptors}

Melatonin was first isolated and identified by Lerner and coworkers in 1958 [48]. This methoxyindole is synthesized and released to the circulation by the pineal gland. The synthesis of melatonin that occurs in a number of other tissues and cells does not contribute significantly to the circulating melatonin levels but rather exerts an autocrine or paracrine role. Within this category, melatonin synthesis by lymphocytes [49], skin [50], the gastrointestinal tract [51], thymus [52], several parts of the eye [53] or bone marrow [54] should be mentioned.

Tryptophan serves as the precursor for the biosynthesis of melatonin. It is converted into serotonin via 5hydroxytryptophan. Serotonin is then acetylated to form $\mathrm{N}$-acetylserotonin through the action of arylalkylamine $\mathrm{N}$ acetyltransferase, one of the key enzymes in melatonin synthesis. $\mathrm{N}$-acetylserotonin is then converted to melatonin by hydroxyindole-O-methyltransferase (HIOMT), which has been identified as a rate-limiting enzyme in the biosynthesis of pineal melatonin $[55,56]$.

Once formed, melatonin is not stored within the pineal gland but diffuses into the capillary blood and cerebrospinal fluid [57]. In a recent study conducted in humans, CSF melatonin levels were found to be higher in the third ventricle compared to the lateral one, thus indicating that melatonin enters the CSF through the pineal recess, even during daytime [58]. The brain has much higher concentrations of melatonin than any other tissue in the body [59].

In the circulation, melatonin is partially bound to albu$\min [60]$ and can also bind to hemoglobin [61]. Circulating melatonin is metabolized mainly in the liver where it is first hydroxylated by cytochrome $\mathrm{P}_{450}$ mono-oxygenases (isoenzymes CYP1B1, CYP1A2, CYP1A1) and, thereafter, conjugated with sulphate to be excreted as 6-sulfatoxymelatonin. Under certain circumstances, 6-sulfatoxymelatonin may be also synthesized in the brain. Melatonin can be metabolized nonenzymatically in all cells of the body. It is converted into 3-hydroxymelatonin when it scavenges two ${ }^{\circ} \mathrm{OH}$ [62]. In the brain, melatonin can be metabolized to kynuramine derivatives [63], particularly under inflammatory conditions. These metabolites of melatonin which are formed in the brain, namely, $N^{1}$-acetyl- $N^{2}$-formyl-5-methoxy kynuramine (AFMK) and $N^{1}$-acetyl-5-methoxykynuramine (AMK), also share the antioxidant and anti-inflammatory properties of melatonin [64, 65].

Melatonin is involved in the control of various physiological functions of the body such as seasonal control of reproductive processes [66, 67], sleep regulation [68], immune mechanisms $[69,70]$, and regulation of circadian $[71,72]$ and sleep-wake rhythms $[73,74]$. In addition to the above-mentioned physiological actions, melatonin in pharmacological doses inhibits tumor growth and may have a potential therapeutic value in treating breast cancer, prostate cancer, melanoma, and cancer of GI tract $[75,76]$. Melatonin also exerts antinociceptive and antiallodynic actions [77]. As the prototype of the chronobiotic class of drugs [74, 78-80], melatonin regulates the phase and amplitude of circadian rhythmicity by interaction with $\mathrm{MT}_{1}$ and $\mathrm{MT}_{2}$ receptors expressed in the hypothalamic suprachiasmatic nuclei (SCN) and other brain areas.

Melatonin exerts many of its actions via membrane receptors, namely, $\mathrm{MT}_{1}$ and $\mathrm{MT}_{2}$ receptors that are expressed both singly and together in various tissues of the body [81-83]. A third melatonin binding site that was isolated and purified from hamster kidney has been characterized as quinone reductase type 2 [84]. This enzyme belongs to a group of reductases that participate in the protection against oxidative stress by preventing electron transfer reactions of quinones. Melatonin is also a ligand for retinoid orphan nuclear receptors [85-87].

The melatonin $\mathrm{MT}_{1}$ receptor is coupled to different $\mathrm{G}$ proteins that mediate adenylyl cyclase inhibition and phospholipase $\mathrm{C}$ activation [83]. The $\mathrm{MT}_{2}$ receptor is coupled to a number of signal transduction mechanisms among them phosphoinositide production, inhibition of adenylyl cyclase, and inhibition of guanylyl cyclase [83].

\section{Melatonin's Free Radical Scavenging and Antioxidant Actions}

Because of its amphiphilic properties, melatonin passes through all biologic barriers with ease. Melatonin gets access freely to all compartments of the cell, and can be especially concentrated in the nucleus and mitochondria $[15,47,88]$.

The discovery that melatonin was a remarkably potent scavenger of the particularly reactive, mutagenic, and carcinogenic ${ }^{\bullet} \mathrm{OH}[89]$ was the finding that initiated numerous studies on melatonin's role as a protector against free radicals. Melatonin was shown to be much more specific than its structural analogs in undergoing reactions which lead to the termination of the radical reaction chain and in avoiding pro-oxidant, C- or O-centered intermediates [89-91]. Moreover, melatonin scavenged numerous different free radical species and other oxidants, among which the 
carbonate radical [92] is important because of its presumed role in mitochondrial damage [93].

Although direct radical scavenging has been effective under numerous experimental conditions at clearly supraphysiological melatonin concentrations, its relevance at physiological levels has been questioned for reasons of stoichiometry. Even though a single melatonin molecule may generate products in a scavenger cascade which may collectively eliminate up to ten free radicals [94], such findings from chemical systems may not be fully applicable to physiological conditions.

In spite of this criticism, melatonin has been shown to protect from oxidotoxicity already at physiological concentrations [95]. A possible indirect action as mediated by upregulation of antioxidant enzymes by melatonin was proposed (reviewed in $[96,97]$ ).

An alternate concept has been put forth to explain the protective effect at the level of radical generation rather than detoxification of already formed radicals [98-100]. If melatonin is capable of decreasing the processes leading to enhanced radical formation, this might be achieved by low, physiological, concentrations of the methoxyindole. Apart from oxidants released by leukocytes, the isoforms of $\mathrm{NAD}(\mathrm{P}) \mathrm{H}$ oxidases (Nox) and mitochondria should be mentioned as main sources of free radicals in the cell. Nox isoenzymes contribute to superoxide formation in a quantitatively substantial manner [101-104]. A recent study showed that melatonin inhibits free radical formation in microglia exposed to amyloid- $\beta_{1-42}$ by preventing the phosphorylation of the p47 Nox subunit via the PI3K/Akt pathway [105] thus giving support to the hypothesis that melatonin has a protective effect at the level of radical generation.

\section{Melatonin and Mitochondrial Function}

Melatonin's ability to influence mitochondrial function has been tested both in vivo and in vitro. In initial in vivo studies conducted on rats, ETC complexes from the mitochondria of brain and liver tissues were measured following injections of melatonin $(10 \mathrm{mg} / \mathrm{kg})$. Melatonin was found to increase the activity of C-I and C-IV of mitochondrial ETC in a time-dependent manner, C-II and C-III not being affected. The effect of melatonin was observed $30 \mathrm{~min}$ after melatonin treatment [15]. Ruthenium red was found to impair mitochondrial metabolism by reducing ETC and ATP synthesis through its cellular oxidative stress action. Inhibition of both C-I and C-IV of the ETC were noted. Injections of melatonin were found to counteract the inhibitory effect of ruthenium red on C-I, C-IV, and GPx enzyme [15].

In an in vitro study, the effect of melatonin on t-butyl hydroperoxide- ( $\mathrm{t}$-BHP-) induced mitochondrial oxidative stress was evaluated. t-BHP depletes mitochondrial GSH and inhibits GPx and GRd activities [106]. In mitochondrial preparations, $100 \mathrm{nM}$ melatonin was found to prevent the oxidation of GSH to GSSG induced by t-BHP and also restored the normal activities of both GPx and GRd [14]. Melatonin increased C-I and C-IV in a dose-dependent manner, the effect being significant at $1 \mathrm{nM}$. Melatonin also counteracted cyanide-induced inhibition of C-IV showing thereby that melatonin can increase the activity of ETC coupled to OXPHOS and increase ATP synthesis in normal mitochondria as well as in mitochondria depleted of ATP by cyanide [14]. The effects of melatonin in regulating Complexes I and IV presumably do not reflect its antioxidant role but indicates an interaction with ETC complexes by donating and accepting electrons, thereby increasing electron flow, an effect not shared by other antioxidants.

The major consequence of melatonin's action on mitochondria may be avoidance of damage and dysfunction thus contributing to increase ATP production $[16,107]$. Melatonin increases the efficiency of ETC thereby limiting electron leakage and free radical generation, and consequently promoting protein synthesis $[17,47]$.

The possible mechanism by which melatonin controls mitochondrial respiration in the liver was examined in two groups of rats [108]. In one group, melatonin (16 to $50 \mu \mathrm{g} / \mathrm{mL}$ ) or vehicle was administered for a period of 45 days. In another study, rats received melatonin in drinking water $(50 \mu \mathrm{g} / \mathrm{mL})$ for 45 days or the same amount for 30 days, followed by a withdrawal period of 15 days. At sacrifice, the liver mitochondrial fraction was prepared and oxygen consumption was measured in the presence of excess concentration DL-3 $\beta$-hydroxybutyrate or L-succinate. Melatonin treatment decreased Krebs's cycle substrate-induced respiration significantly at both examined doses. The stimulation of mitochondrial respiration, caused by excess concentration of substrate, recovered after melatonin withdrawal. Basal state 4 respiration was not modified by melatonin. This study shows that melatonin can protect mitochondria from oxidative damage resulting from overstimulation of cellular respiration caused by excess Krebs' cycle substrate [108].

A similar study on melatonin's mechanism of action on mitochondrial respiration was carried out by another group of investigators [18]. In this study, mitochondria from mouse liver cells was incubated in vitro with melatonin at concentrations ranging from $1 \mathrm{nM}$ to $1 \mathrm{mM}$. Melatonin decreased oxygen consumption, inhibited the increase in oxygen flux in the presence of excess of ADP, reduced membrane potential and inhibited the production of $\mathrm{O}_{2}{ }^{--}$and $\mathrm{H}_{2} \mathrm{O}_{2}$. Melatonin was also able to maintain the efficiency of oxidative phosphorylation and ATP synthesis by increasing the activity of the respiratory complexes I, III, and IV. These effects were attributed to the intramitochondrial presence of melatonin, thus showing melatonin's participation in the physiological regulation of mitochondrial homeostasis [18].

Melatonin's action in preventing the opening of the mtPT pore given by oxidative stress caused by $t$-BHP was shown in another study on primary skeletal muscle cultures [109]. Using isolated mitochondria, melatonin $(1-100 \mu \mathrm{M})$ fully prevented myotube death induced by t-BHP. Melatonin desensitized the mtPT pore to $\mathrm{Ca}^{2+}$ and prevented t-BHPinduced mitochondrial swelling and GSH oxidation. The inhibition of the mtPT pore opening by melatonin was suggested as an explanation for the protective action of melatonin against oxidative stress in myotubes [109]. 
Recently, the role of melatonin on cardiolipin and mitochondrial bioenergetics was explored [110, 111]. Cardiolipin, a phospholipid located at the level of inner mitochondrial membrane, is required for several mitochondrial bioenergetic processes as well as in mitochondrial-dependent steps of apoptosis. Alterations in cardiolipin structure, content, and acyl chain composition have been associated with mitochondrial dysfunction in various tissues under a variety of pathophysiological conditions [110]. Melatonin was reported to protect the mitochondria from oxidative damage by preventing cardiolipin oxidation and this may explain, at least in part, the beneficial effect of this molecule in mitochondrial physiology $[110,111]$.

5.1. Melatonin and Mitochondrial Dysfunction in Aging. The enhanced production of ROS and accumulation of mtDNA mutations in mitochondria may be contributory factors to human aging [112]. Many studies have established that the respiratory function of mitochondria declines with age [113115]. The increased production of free radicals such as $\mathrm{O}_{2}{ }^{\bullet-}$ and $\mathrm{H}_{2} \mathrm{O}_{2}$ in mitochondria along with advancing age has been demonstrated $[116,117]$. Accumulation of mtDNA mutations can cause defective respiratory function resulting in enhanced production of ROS. Many of these mtDNA mutations begin after adults reach their the mid thirties and accumulate with age in postmitotic tissues [115].

Overproliferation of abnormal mitochondria has been shown to occur in the muscle of aged individuals and in patients with mitochondrial myopathies $[115,118]$. The presence of these defective mitochondria is one of the factors involved in the decline in respiratory function during the aging process [115].

Enhanced activation of the mtPT pore in the brain and liver of aging mice has also been demonstrated [119]. This in turn causes the release of proapoptotic factors from the intermembrane space of mitochondria. Hence, an increased mitochondrial ROS production, oxidative stress, respiratory functional decline, and susceptibility to apoptosis constitute central events in the aging process [115].

The mechanism of the aging process can be studied in experimental models like the senescence accelerated mouse (SAMP8) and senescence resistant mouse (SAMR1). The SAMP8 is an established murine model of accelerated aging [120]. The accelerated aging seen in this mouse strain is due to oxidative stress, which occurs with greater intensity as compared to the SAMR1 [121]. At an age of 12 months, reductions in the activities of respiratory complexes I and IV have been demonstrated in liver mitochondria of SAMP8 mice, but not in SAMR1 mice [122]. Greater concentrations of lipid peroxidation products in the liver and brain homogenates were found in SAMP8 mice as compared to SAMR1 mice. In contrast to this, the concentration of the antioxidant enzyme GPx from SAMP8 mice at 12 months of age was found to be significantly lower than in SAMR1 mice. These studies support the conclusion that excess free radical generation coupled with less effective defense against the oxidative stress is responsible for alteration of mitochondrial function seen in SAMP 8 mice [122-124].
Since melatonin can readily reach the mitochondria due to its high lipophilicity, it seems feasible that, upon its entry into the cell, it could become concentrated at a superficial position in lipid layers near the polar heads of membrane phospholipids, a key place to function as a free radical scavenger [125]. The effect of melatonin on agedependent changes in the redox status of mitochondria in the heart and diaphragm was thus evaluated [126]. Melatonin, administered in the drinking water at a dose of $10 \mathrm{mg} / \mathrm{kg}$ for 9 months, was shown (i) to counteract the age-dependent increase in lipoperoxidation level, (ii) to increase GSH content in muscle mitochondria of both SAMP8 and SAMR1 mice, (iii) to counteract the reduction of GSH/GSSG ratio in diaphragmatic mitochondria of SAMR1 and SAMP8 mice, (iv) to increase the activity of the antioxidant enzymes GPx and GRd in the mitochondria of SAMP8 mice with no effect on SAMR 1 mice, and (v) to increase the activity of GRd in SAMR1 mice. Therefore, long-term melatonin administration prevented the age-dependent mitochondrial stress in both senescence-accelerated and senescence-resistant mice [126].

As a continuation of the above-mentioned study, the effect of melatonin at earlier stages of the life span was evaluated at the 5th and 10th months of age in SAMP8 and SAMR1 mice [127]. Mitochondrial oxidative stress was determined by measuring the levels of lipid peroxidation, GSH and GSSG, and the activities of GPx and GRd in diaphragmatic mitochondria. Age did not affect diaphragmatic mitochondrial levels of lipid peroxidation in SAMR1 mice but increased them in SAMP8 animals. When melatonin was administered in the drinking water at a daily dose of $10 \mathrm{mg} / \mathrm{kg}$, the level of lipid peroxidation in 10-month-old SAMP8 mice was reduced to that found at 5 months of age. The decrease of GPx seen with age in both strains of mice was counteracted by melatonin administration with a higher effect in SAMP8 mice. As far as GRd, although age caused significant reductions in both strains of mice, treatment with melatonin partially restored GRd activity in SAMR1 mice only. The chronic administration of melatonin significantly increased complex II and complex III activity in SAMR1 and SAMP 8 mice and complex IV activity in SAMP 8 mice [127].

Measurement of ATP levels and ATP/ADP ratio showed that treatment with melatonin counteracted the reduction in ATP levels and ATP/ADP ratio found in SAMP8 mice. As far as longevity, melatonin treatment increased the halflife of SAMP8 mice from 16 to 22 months while longevity increased from 23 to 27 months [127]. Melatonin's beneficial effects on longevity were significantly higher in SAMP8 mice than in SAMR1 mice. The study thus showed that melatonin administration counteracted age-dependent oxidative damage and mitochondrial dysfunction in senescence accelerated mice by improving mitochondrial function as reflected by the increase in ATP production and a prolonged longevity [127].

Another study using rat brain mitochondria was designed to evaluate the beneficial effects of melatonin on age-associated reductions in mitochondrial bioenergetic function [111]. Mitochondria from control and aged rats treated or not with melatonin were obtained, and various 
bioenergetic parameters such as complex I activity, rates of state 3 respiration, mitochondrial $\mathrm{H}_{2} \mathrm{O}_{2}$ production, and membrane potential were evaluated. Melatonin was found to prevent the significant age-related changes that occurred in all of these parameters in untreated animals. The ability to prevent complex I dysfunction and cardiolipin peroxidation was melatonin's principal mechanism of action for achieving its effects [111].

Age-associated impairments in mitochondrial OXPHOS found in the brain of SAMP8 mice did not exhibit any major gender differences [128]. However, a higher reduction in the GSH/GSSG ratio at 10 months of age in female than in male SAMP8 mice has been reported in one study [129]. Chronic melatonin treatment completely prevented age-dependent oxidative stress as assessed by the recovery of the GSH/GSSG in mitochondria of brain samples of both male and female mice [129]. The ability of melatonin to prevent GSH loss with age probably reflects its influence on the activities of the GSH redox cycle enzymes [47].

An impairment of the mitochondrial respiratory chain activity occurs with age. This is not due to reduction of brain mitochondria with aging but has been demonstrated to be due to diminished activities of respiratory complexes I, II, and III [130]. Mitochondrial dysfunction with aging is not an irreversible process as shown by studies using melatonin to prevent age-dependent declines in bioenergetic impairment of brain mitochondria in mice [129].

5.2. Melatonin and Mitochondrial Function in $I / R$. I/R lesions are seen in many clinical conditions and are triggered by multiple factors including overproduction of ROS [131133]. For example, ROS produced at the level of complex I and III of the respiratory chain are responsible for injury seen in cardiac I/R [134, 135] as well as in stroke [133].

The available evidence indicates the opening of the $\mathrm{mtPT}$ pore is responsible for the cardiomyocyte death occurring during I/R [136]. While these pores remain closed during the ischemic period, at reperfusion the influx of $\mathrm{Ca}^{2+}$ into the mitochondria and an associated burst of ROS production caused the opening of mtPT channels. This leads to mitochondrial depolarization, swelling, and rupture of the external mitochondrial membrane, with uncoupling of the respiratory chain and efflux of cytochrome $\mathrm{C}$ and other proapoptotic factors, all of which lead to either cell death by either apoptosis or necrosis.

Melatonin has also been shown to be effective in protecting the cardiac musculature against I/R [137-139]. Melatonin's protective effect during I/R has been attributed to its action in inhibiting the mtPT pore [140], and in preserving the content and integrity of cardiolipin molecules [141]. Melatonin treatment resulted in significant reductions in infarct size [142].

The fact that melatonin treatment inhibits both mtPT pore opening and cardiolipin peroxidation following $\mathrm{I} / \mathrm{R}$ suggests a possible link between these two processes. It has been suggested that that increased levels of peroxidized cardiolipin together with increased $\mathrm{Ca}^{2+}$ overload can contribute to the $\mathrm{mtPT}$ pore opening during reperfusion [143].
Melatonin, by preventing the oxidative damage of cardiolipin, prevents $\mathrm{mtPT}$ channel opening. It must be noted that a significant cytoprotective effect of melatonin was described at a very early phase of a myocardial infarction, when I/R and thus oxidative damage were minimal [144], indicating that not all cardiac protective effects of melatonin are attributable to its antioxidant activity.

5.3. Melatonin and Mitochondrial Dysfunction in Sepsis. Septic shock is a lethal condition caused by a complex chain of pathogen-induced events involving immune cells, the epithelium, the endothelium, and the neuroendocrine system. The lethal effects of septic shock are associated with the production and release of numerous proinflammatory mediators as well as NO and ROS, thus inducing massive apoptosis.

Since many years ago, research interest was focused on the hypothesis that mitochondrial dysfunction plays a pivotal role in septic shock. This hypothesis was indeed confirmed by the finding of decreased respiratory complex I activity and low levels of ATP levels in skeletal muscle biopsies obtained from critically ill patients with septic shock [145]. Increased NO production and decreased levels of GSH were also found in septic shock patients.

The protective effect of melatonin on the lethal effects of bacterial lipopolysaccharide (LPS) on respiratory complex activities I and IV and a mitochondrial subform of iNOS ( $\mathrm{mt}$ iNOS) activity was examined in liver and lung mitochondria of rats [146]. LPS administered at a dose of $10 \mathrm{mg} / \mathrm{kg}$ i.v. was found to increase mt iNOS activity and NO, an effect that was greater in old rats than in young ones. LPS also decreased the activities of respiratory complexes I and IV. Melatonin administration $(60 \mathrm{mg} / \mathrm{kg}$, i.p.) prevented LPS toxicity by decreasing mt iNOS activity and NO production. It also counteracted LPS-induced inhibition of the activity of respiratory complexes I and IV. It is interesting to note that the effectiveness of melatonin to prevent the mitochondrial failure that occurs during endotoxemia were more pronounced in older animals than in young ones [146].

Using a long-term (3-day) rat model of sepsis, a number of parameters of mitochondrial dysfunction were investigated. The model comprises a long-term, fluid-resuscitated, fecal peritonitis model utilizing male Wistar rats that closely replicates human physiological, biochemical, and histological findings with a $40 \%$ mortality [8]. Compared to sham-operated controls severely septic rats had lower (20$22 \%)$ hepatic and muscle complex I activities. Moderate increases in nitrite/nitrate production were seen in both muscle and liver peaking at $24-48 \mathrm{~h}$ and returning to shamoperated levels at $72 \mathrm{~h}$. A fall in GSH was associated with lower complex I and increased NO production was also demonstrated [8]. A number of animal model studies and a few clinical observations have now shown that melatonin is beneficial for treating septic shock (see, for a recent review, [147]).

To examine the effect of melatonin on changes in $\mathrm{mt}$ iNOS in septic skeletal muscles wild-type $\left(\mathrm{iNOS}^{+/+}\right)$and iNOS knockout $\left(\mathrm{iNOS}^{-/-}\right.$) mice were turned septic by the 
cecal ligation and puncture procedure [148]. After sepsis, increases in $\mathrm{mt}$ iNOS and NO levels, and decreases in electron chain activity were noted in $\mathrm{iNOS}^{+/+}$mice but not in $\mathrm{iNOS}^{-/-}$mice. In addition, an increase in oxidative stress was also found as indicated by an increase in lipid peroxidation products as well as a reduction in GSH levels and in the activities of GPx and GRd. Melatonin treatment counteracted the changes in $\mathrm{mt}$ iNOS activities and oxidative stress, and, further, restored the mitochondrial respiratory chain in $\mathrm{iNOS}^{+/+}$mice [148]. This study confirmed that mtNOS is responsible for the mitochondrial dysfunction seen during sepsis and thus supported the conclusion that melatonin has the ability to protect against $\mathrm{mt}$ iNOSmediated mitochondrial failure. A similar study performed in mitochondria isolated from the diaphragm of septic mice indicated that melatonin administration to $\mathrm{iNOS}^{+/+}$ mice counteracted $\mathrm{mt}$ iNOS induction and respiratory chain failure, and, finally, normalized the redox state after sepsis [149].

Considering the effects of melatonin and its virtual absence of toxicity, the use of melatonin along with conventional therapy to preserve mitochondrial bioenergetics as well as to limit inflammatory response and oxidative damage should be taken into account as a treatment option [147].

5.4. Melatonin and Mitochondrial Dysfunction in PD. PD is a neurodegenerative disorder with a multifactorial etiology, mainly characterized by the death of dopaminergic neurons in the pars compacta of substantia nigra and by the formation of Lewy bodies. The initiating factor in PD is increased release of free radicals and enhanced signs of oxidative stress as demonstrated in brains of PD patients [150-152].

Although the molecular mechanisms responsible for the pathogenesis of $\mathrm{AD}$ are still under intense investigation [128], reduced complex I activity in the substantia nigra [153] and loss of GSH [154] have been reported in PD patients. The selective inhibition of complex I in the ETC compromises energy availability and leads to apoptosis and death of the dopaminergic cells of substantia nigra.

A commonly accepted model of PD is that achieved by the systemic or intracerebral administration of neurotoxins like 1-methyl-4-phenyl-1,2,3,6 tetrahydropyridine (MPTP). The loss of dopamine neurons occurring in these animal models causes severe sensory and motor impairment which in turn gives rise to tremor, rigidity and akinesia similar to those seen in PD patients $[155,156]$. The active glial metabolite of MPTP, 1-methyl-4-phenylpyridinium $\left(\mathrm{MPP}^{+}\right)$, is taken up into the dopaminergic neurons through the dopamine transporter, and then accumulates in the mitochondria of substantia nigra pars compacta [157]. By binding to complex I, $\mathrm{MPP}^{+}$increases the production of ROS and enhances oxidative stress causing reduction of ATP and death of cells in the substantia nigra [157].

In the striatum, the damage caused by $\mathrm{MPP}^{+}$is attributed to increased generation of $\mathrm{O}_{2}{ }^{--}$that reacts with $\mathrm{NO}$ to generate the highly toxic $\mathrm{ONOO}^{-}$. This impairs mitochondrial function as a result of irreversible inhibition of all ETC complexes [158] leading to the death of neuronal cells [159].
A neuroprotective effect of melatonin in isolated rat striatal synaptosomes and liver mitochondria treated with $\mathrm{MPP}^{+}$has been demonstrated [160]. Melatonin prevented the inhibition of mitochondrial respiration by limiting the interaction of $\mathrm{MPP}^{+}$with complex I of ETC.

Although the role of ROS generation has been demonstrated in the etiology of PD, the participation of mtNOS in the mitochondrial dysfunction and nigrostriatal degeneration has only recently been examined [128]. In a study conducted in adult male mice, MPTP was administered at a dose of $15 \mathrm{mg} / \mathrm{kg}$ in four separate doses [161]. Animals also received melatonin or its metabolite AMK $(20 \mathrm{mg} / \mathrm{kg}) 1 \mathrm{~h}$ prior to MPTP injection. The administration of melatonin or AMK concomitantly with MPTP significantly reduced the iNOS activity stimulated by MPTP.

In the mitochondria, two NOS isoforms, namely, constitutive and inducible, may exist. MPTP administration significantly increased the activity of mt iNOS without affecting mt constitutive NOS activity. Treatment with melatonin or AMK restored the basal activity of i-mtNOS. Interestingly, MPTP administration induced i-mtNOS activity in the mitochondria of substantia nigra whereas i-mtNOS was only slightly induced by MPTP in striatal mitochondria. Treatment with either melatonin or its brain metabolite AMK effectively counteracted i-mtNOS induction, oxidative stress, and mitochondrial dysfunction induced by MPTP [161]. The nitrosative/oxidative stress reduction seen after therapeutic intervention with melatonin or AMK in MPTP treated mice was attributed to an effect in preventing damage to mitochondria. As already mentioned, mitochondria take up melatonin in a concentration- and time-dependent manner [18].

A small number of controlled trials indicate that melatonin is useful to treat disturbed sleep in PD $[162,163]$, particularly rapid eye movement-associated sleep behavior disorder [164-169]. Whether melatonin or the recently introduced melatonergic agents (ramelteon, agomelatine) have the potential for treating insomnia in PD patients and, more generally, for arresting the progression of PD merits further investigation.

5.5. Melatonin and Mitochondrial Dysfunction in AD. Several recent studies have confirmed the involvement of mitochondrial ROS production and abnormal mitochondrial function in the pathophysiology of $\mathrm{AD}$ [170-177]. AD is characterized by extracellular senile plaques of aggregated $\beta$-amyloid $(\mathrm{A} \beta)$ and intracellular neurofibrillary tangles that contain hyperphosphorylated tau protein. The resulting clinical effect is a progressive loss of memory and deterioration of cognition.

$\mathrm{A} \beta$ is reported to accumulate in subcellular compartments and to impair neuronal function [178]. There is substantial evidence to prove that mitochondrial toxicity is linked to the progressive accumulation of mitochondrial $\mathrm{A} \beta$ [179]. In the early phase of $\mathrm{AD}$, inhibitors of $\beta$ and $\gamma$ secretase can be therapeutically effective to halt $\mathrm{AD}$ disease progression by inhibition of the protein misfolding of $\mathrm{A} \beta$ into neurotoxic oligomeric aggregates. 
TABLE 1: Melatonin activity in bioenergetic functions: evidence from in vitro and in vivo studies.

\begin{tabular}{|c|c|c|c|}
\hline $\begin{array}{l}\text { Animal model studies } \\
\text { (in vitro and in vivo) }\end{array}$ & Pretreatment & Posttreatment with melatonin & Reference(s) \\
\hline $\begin{array}{l}\text { Ruthenium red-effect on } \\
\text { ETC system }\end{array}$ & $\begin{array}{l}\text { Inhibition of complex I and IV and } \\
\text { impairment of ATP synthesis }\end{array}$ & $\begin{array}{l}\text { Counteracted ruthenium red's } \\
\text { inhibitory action complex I and IV }\end{array}$ & {$[15]$} \\
\hline $\begin{array}{l}\text { t-BHP treated mitochondrial } \\
\text { preparations }\end{array}$ & $\begin{array}{l}\text { Depletion of mitochondrial GSH; } \\
\text { inhibition of GPx and GRd activities }\end{array}$ & $\begin{array}{l}\text { Prevented the oxidation of GSH to } \\
\text { GSSG, restored GPx and GRd back to } \\
\text { normal }\end{array}$ & {$[14]$} \\
\hline $\begin{array}{l}\text { MPTP effect on isolated } \\
\text { striatal synaptosomes and } \\
\text { liver mitochondria }\end{array}$ & Inhibition of ETC complex I & $\begin{array}{l}\text { Prevented MPTP-induced inhibition } \\
\text { of complex I }\end{array}$ & {$[160]$} \\
\hline SAMP- 8 mice & Elevated lipid peroxidation products & Reduced lipid peroxidation & [122] \\
\hline LPS-injected rats & $\begin{array}{l}\text { Increased mitochondrial NOS. NO } \\
\text { decreased ETC complex I and IV }\end{array}$ & $\begin{array}{l}\text { Decreased NO production and } \\
\text { counteracted LPS-induced inhibition } \\
\text { of complex I an IV }\end{array}$ & {$[146]$} \\
\hline $\begin{array}{l}\text { Ischemia-reperfusion effect } \\
\text { on mitochondria }\end{array}$ & $\begin{array}{l}\text { Opens mtPT pores and destroys } \\
\text { cardiolipin in mitochondria }\end{array}$ & $\begin{array}{l}\text { Inhibits } \mathrm{mtPT} \text { pore opening and } \\
\text { preserves the structural complex of } \\
\text { cardiolipin in mitochondria }\end{array}$ & {$[140]$} \\
\hline $\begin{array}{l}\text { Mitochondria from heart } \\
\text { and diaphragm muscle of } \\
\text { SAMP-8 mice }\end{array}$ & $\begin{array}{l}\text { Increased LPO; decrease in GSH } \\
\text { levels and GPx and GRd activities }\end{array}$ & $\begin{array}{l}\text { Counteracted age-dependent } \\
\text { increase in LPO and reduction of } \\
\text { GSH, GPx, and GRd }\end{array}$ & {$[125]$} \\
\hline $\begin{array}{l}\text { Skeletal muscle of septic } \\
\text { wild-type }\left(\mathrm{iNOS}^{+/+}\right) \text {and } \\
\text { iNOS knockout }\left(\mathrm{iNOS}^{-/-}\right) \\
\text {mice }\end{array}$ & $\begin{array}{l}\text { Increase of mt iNOS and NO levels, } \\
\text { increase of lipid peroxidation } \\
\text { products, decrease of GSH levels and } \\
\text { of GPx and GRd activities }\end{array}$ & $\begin{array}{l}\text { Decreased mt iNOS and NO levels, } \\
\text { counteracted reduction of GSH, GPx } \\
\text { and GRd }\end{array}$ & {$[148]$} \\
\hline $\begin{array}{l}\text { Diaphragmatic muscle of } \\
\text { septic wild type }\left(\mathrm{iNOS}^{+/+}\right) \\
\text {and iNOS knockout } \\
\left(\mathrm{iNOS}^{-/-}\right) \text {mice }\end{array}$ & $\begin{array}{l}\text { Increase of mt iNOS and NO levels, } \\
\text { reduction of GSH and of GPx and } \\
\text { GRd activities }\end{array}$ & $\begin{array}{l}\text { Decreased mt iNOS and NO levels; } \\
\text { counteracted reduction of GSH, GPx, } \\
\text { and GRd }\end{array}$ & [149] \\
\hline Mitochondria from rat liver & Normal ETC function & $\begin{array}{l}\text { Melatonin treatment decreased } \\
\text { Krebs's cycle substrate-induced } \\
\text { respiration. }\end{array}$ & {$[108]$} \\
\hline $\begin{array}{l}\text { Heart and diaphragmatic } \\
\text { muscle of SAMP- } 8 \text { mice }\end{array}$ & $\begin{array}{l}\text { Decreased levels of GSH and of GPx } \\
\text { and GRd activities, increased lipid } \\
\text { peroxidation }\end{array}$ & $\begin{array}{l}\text { Increased GSH levels and GPx and } \\
\text { GRd activities; decreased lipid } \\
\text { peroxidation products }\end{array}$ & {$[126]$} \\
\hline $\begin{array}{l}\text { Diaphragmatic muscle of } \\
\text { SAMP-8 mice-effect of aging }\end{array}$ & $\begin{array}{l}\text { Decrease of GSH and GPx, GRd, } \\
\text { increase in lipid peroxidation }\end{array}$ & $\begin{array}{l}\text { Counteracted age-dependent } \\
\text { decrease in GSH, GPx, and GRd } \\
\text { Normalized lipid peroxidation }\end{array}$ & {$[127]$} \\
\hline $\begin{array}{l}\text { Mitochondria from liver of } \\
\text { normal mice }\end{array}$ & $\begin{array}{l}\text { Normal function of ETC complexes; } \\
\text { opening of mtPT pores after } \\
\text { oxidative stress }\end{array}$ & $\begin{array}{l}\text { Increased complex I, III, and IV; } \\
\text { closing of the mtPT pores opened by } \\
\text { oxidative stress }\end{array}$ & {$[18]$} \\
\hline $\begin{array}{l}\text { t-BHP effect on } \\
\text { mitochondria of skeletal } \\
\text { muscle }\end{array}$ & $\begin{array}{l}\text { Opening of mtPT and death of } \\
\text { myotubules }\end{array}$ & $\begin{array}{l}\text { Prevented t-BHP-induced opening of } \\
\text { mtPT pores and swelling of } \\
\text { mitochondria }\end{array}$ & [109] \\
\hline $\begin{array}{l}\text { MPTP effect on } \\
\text { mitochondria of neurons in } \\
\text { substantia nigra of mice }\end{array}$ & $\begin{array}{l}\text { Increased mt iNOS; increased } \\
\text { oxidative stress }\end{array}$ & $\begin{array}{l}\text { Counteracted MPTP-induced } \\
\text { increase of iNOS in substantia nigra } \\
\text { and reduced the oxidative stress }\end{array}$ & {$[161]$} \\
\hline $\begin{array}{l}\text { Effect of } \\
\text { ischemia-reperfusion on } \\
\text { mitochondria }\end{array}$ & $\begin{array}{l}\text { Opening of mtPT pores and } \\
\text { oxidation of cardiolipin }\end{array}$ & $\begin{array}{l}\text { Inhibited mtPT pores and cardiolipin } \\
\text { oxidation }\end{array}$ & {$[110,143]$} \\
\hline $\begin{array}{l}\text { Effect of } A \beta \text { on hippocampal } \\
\text { neurons }\end{array}$ & $\begin{array}{l}\text { Inhibition of ETC; reduced ATP } \\
\text { levels }\end{array}$ & $\begin{array}{l}\text { Attenuated } \mathrm{A} \beta \text {-induced inhibition of } \\
\text { respiratory complexes; restored ATP } \\
\text { levels }\end{array}$ & [187] \\
\hline
\end{tabular}

Abbreviations used: A $\beta$ : $\beta$ amyloid; ETC: electron transport chain; GPx: glutathione peroxidase; GRd: glutathione reductase; GSH: reduced glutathione; GSSG: oxidized glutathione; iNOS: inducible nitric oxide synthase; LPS: lipopolysaccharide; MPTP: 1-methyl-4-phenyl-1,2,3,6 tetrahydropyridine; mt iNOS: mitochondrial inducible nitric oxide synthase; mtPT: mitochondrial permeability transition; NO: nitric oxide; SAMP-8 mice: senescence accelerated mouse; t-BHP: t-butyl hydroperoxide. 
Mitochondrial $\mathrm{O}_{2}{ }^{\bullet-}$ production plays a critical role in the pathological events following A $\beta$ elevation. An increased expression of mitochondrial antioxidant enzyme SOD-2 has been shown to prevent memory deficits and amyloid plaque deposition associated with AD [172]. Although a hypothetical occurrence of mutations in mtDNA could cause increased oxidative stress and energy failure, no causative mutations in mtDNA have been detected in $\mathrm{AD}$ so far [180].

Several actions of melatonin have been described which antagonize the deleterious effects of $\mathrm{A} \beta$. The effects of melatonin can be grouped as (i) antioxidant, including influences on mitochondrial metabolism; (ii) antifibrillogenic, blocking $\mathrm{A} \beta$ synthesis; (iii) cytoskeletal, including suppression of tau protein hyperphosphorylation (for a recent review see [181]). The antifibrillogenic effects of melatonin were observed not only in vitro but also in vivo in transgenic mouse models [182-184]. Protection from A $\beta$ toxicity was observed, especially at the mitochondrial level.

Melatonin also activates the survival signal pathways. One such pathway is the Bcl-2 pathway, which stabilizes mitochondrial function by antiapoptotic Bcl-2 family modulators. Bcl-2-expression was enhanced by melatonin concomitantly with inhibition of $\mathrm{A} \beta$-induced cell death [185]. This in vitro study was mimicked by an in vivo one. Melatonin inhibited free radical formation in microglia exposed to amyloid- $\beta_{1-42}$ by preventing the phosphorylation of the p47 Nox subunit via the PI3K/Akt pathway [105].

In view of the consequences of excitation-dependent calcium overload on mitochondrial membrane potential and $\mathrm{mtPT}$ pore sensitivity towards excitotoxins like $\mathrm{A} \beta$, the actions of melatonin at the level of this important cellular compartment deserve particular attention. Modulation of mitochondrial $\mathrm{Ca}^{2+}$ handling has been suggested as the potential pharmacological target for $\mathrm{AD}$ [186]. In a recent study, a possible melatonin prevention of damage induced by $\mathrm{A} \beta$ was evaluated in young and senescent hippocampal neurons. Rat hippocampal neurons were incubated with $\mathrm{A} \beta_{25-35}$ and cell viability, mitochondrial membrane potential, ATP, and the activity of the respiratory chain complexes were measured [187]. Cells exposed to $A \beta_{25-35}$ showed decreased mitochondrial membrane potential, inhibited activity of respiratory chain complexes, and a depletion of ATP levels. Melatonin attenuated $\mathrm{A} \beta_{25}-35$-induced mitochondrial damage in senescent hippocampal neurons [187]. Molecular studies undertaken with mitochondrial preparations suggest that melatonin has a therapeutic value in treating $\mathrm{AD}$ through its antiapoptotic activities [188].

As outlined, melatonin acts at different levels relevant to the development and manifestation of AD. The antioxidant, mitochondrial, and antiamyloidogenic effects may be seen as a possibility of interfering with the onset of the disease. Therefore, early beginning of treatment may be decisive [189]. Mild cognitive impairment (MCI) is an etiologically heterogeneous syndrome characterized by cognitive impairment shown by objective measures adjusted for age and education in advance of dementia [190]. Some of these patients develop AD. A small number of controlled trials indicate that melatonin is useful to treat MCI and to prevent progression to AD [181, 191-194].
5.6. Melatonin and Mitochondrial Dysfunction in HD. A Huntington's chorea animal model was developed by using 3-nitropropionic acid, an inhibitor of mitochondrial complex II. In this model, that replicates the neurochemical, histological, and clinical features of HD, melatonin administration was reported to defer the clinical signs of HD [195]. Current evidence from genetic models of HD including mutation of the huntingtin gene ( $\mathrm{mHtt})$, supports the mitochondrial dysfunction as major cause of the disease, with respiratory chain impairment relegated to a late secondary event [196]. Upstream events include defective mitochondrial calcium handling and impaired ATP production. Also, transcription abnormalities affecting mitochondria composition, reduced mitochondria trafficking to synapses, and direct interference with mitochondrial structures enriched in striatal neurons, are possible mechanisms by which $\mathrm{mHtt}$ amplifies striatal vulnerability [196]. Evidence is lacking on whether melatonin's action on mitochondria could affect evolution in the genetic model of HD. At least on the accumulation of insoluble protein aggregates in intra- and perinuclear inclusions in HD melatonin had little or no inhibitory effect on huntingtin aggregation [197].

\section{Conclusions}

Mitochondrial dysfunction is implicated as the major causative factor in a variety of conditions such as the aging process, I/R, and septic shock. In addition, abnormal mitochondrial function, decreased respiratory enzyme complex activities, increased electron leakage, opening of the mtPT pore, and increased $\mathrm{Ca}^{2+}$ entry have all been shown to play a role in the pathophysiology of neurodegenerative disorders such as $\mathrm{PD}, \mathrm{AD}$, and $\mathrm{HD}$.

In addition to aging as a factor for low melatonin levels, it is well documented that there is a huge interindividual variation in circulating levels of melatonin which is stable within individuals and, which has been hypothesized to be genetic in origin [198-201]. There is now evidence that there are polymorphisms in the gene for HIOMT, the rate limiting enzyme in melatonin synthesis, and that the HIOMT transcript level depends significantly on the genotype distributions [202]. Thus, there may be a genetically determined low melatonin syndrome that causes a predisposition to a variety of diseases.

Among the number of substances involved in maintaining mitochondrial bioenergetics a number of in vivo and in vitro studies in animals (Table 1 ) indicate that melatonin may emerge as a major therapeutic candidate to preserve the bioenergetic function of mitochondria. Double-blind placebo controlled studies are needed to assess to what extent melatonin has therapeutic value in the treatment of the several disorders associated with mitochondrial dysfunction.

\section{Conflict of Interests}

S. R. Pandi-Perumal is a stockholder and the President and Chief Executive Officer of Somnogen Inc., a New York corporation. He declared no competing interests that might 
be perceived to influence the content of this paper. All remaining authors declare that they have no proprietary, financial, professional, nor any other personal interest of any kind in any product or services and/or company that could be construed or considered to be a potential conflict of interest that might have influenced the views expressed in this paper.

\section{Acknowledgment}

D. P. Cardinali is a Research Career Awardee from the Argentine National Research Council (CONICET), Argentina and Professor Emeritus, University of Buenos Aires, Argentina.

\section{References}

[1] M. F. Beal, "Mitochondrial dysfunction in neurodegenerative diseases," Biochimica et Biophysica Acta, vol. 1366, no. 1-2, pp. 211-223, 1998.

[2] M. F. Beal, "Therapeutic approaches to mitochondrial dysfunction in Parkinson's disease," Parkinsonism and Related Disorders, vol. 15, no. 3, pp. S189-S194, 2009.

[3] D. C. Wallace and W. Fan, "The pathophysiology of mitochondrial disease as modeled in the mouse," Genes and Development, vol. 23, no. 15, pp. 1714-1736, 2009.

[4] D. C. Wallace, "Mitochondrial diseases in man and mouse," Science, vol. 283, no. 5407, pp. 1482-1488, 1999.

[5] E. A. Schon, S. DiMauro, M. Hirano, and R. W. Gilkerson, "Therapeutic prospects for mitochondrial disease," Trends in Molecular Medicine, vol. 16, no. 6, pp. 268-276, 2010.

[6] S. DiMauro and E. A. Schon, "Mitochondrial disorders in the nervous system," Annual Review of Neuroscience, vol. 31, pp. 91-123, 2008.

[7] S. DiMauro and E. A. Schon, "Mitochondrial respiratorychain diseases," New England Journal of Medicine, vol. 348, no. 26, pp. 2656-2668, 2003.

[8] D. Brealey, S. Karyampudi, T. S. Jacques et al., "Mitochondrial dysfunction in a long-term rodent model of sepsis and organ failure," American Journal of Physiology, vol. 286, no. 3, pp. R491-R497, 2004.

[9] G. T. Rezin, G. Amboni, A. I. Zugno, J. Quevedo, and E. L. Streck, "Mitochondrial dysfunction and psychiatric disorders," Neurochemical Research, vol. 34, no. 6, pp. 10211029, 2009.

[10] B. Rollins, M. V. Martin, P. A. Sequeira et al., "Mitochondrial variants in schizophrenia, bipolar disorder, and major depressive disorder," PLoS One, vol. 4, no. 3, Article ID e4913, 2009.

[11] J. Miquel, A. C. Economos, J. Fleming, and J. E. Johnson, "Mitochondrial role in cell aging," Experimental Gerontology, vol. 15, no. 6, pp. 575-591, 1980.

[12] S. Raha and B. H. Robinson, "Mitochondria, oxygen free radicals, disease and ageing," Trends in Biochemical Sciences, vol. 25, no. 10, pp. 502-508, 2000.

[13] M. L. Genova, M. M. Pich, A. Bernacchia et al., "The mitochondrial production of reactive oxygen species in relation to aging and pathology," Annals of the New York Academy of Sciences, vol. 1011, pp. 86-100, 2004.

[14] M. Martin, M. Macias, G. Escames, J. Leon, and D. AcunaCastroviejo, "Melatonin but not vitamins $\mathrm{C}$ and E maintains glutathione homeostasis in t-butyl hydroperoxide-induced mitochondrial oxidative stress," FASEB Journal, vol. 14, no. 12 , pp. 1677-1679, 2000.
[15] M. Martín, M. Macías, G. Escames et al., "Melatonin-induced increased activity of the respiratory chain complexes I and IV can prevent mitochondrial damage induced by ruthenium red in vivo," Journal of Pineal Research, vol. 28, no. 4, pp. 242248, 2000.

[16] M. Martín, M. Macías, J. León, G. Escames, H. Khaldy, and D. Acuña-Castroviejo, "Melatonin increases the activity of the oxidative phosphorylation enzymes and the production of ATP in rat brain and liver mitochondria," International Journal of Biochemistry and Cell Biology, vol. 34, no. 4, pp. 348-357, 2002.

[17] J. Leon, D. Acuña-Castroviejo, R. M. Sainz, J. C. Mayo, D. X. Tan, and R. J. Reiter, "Melatonin and mitochondrial function,” Life Sciences, vol. 75, no. 7, pp. 765-790, 2004.

[18] A. López, J. A. García, G. Escames et al., "Melatonin protects the mitochondria from oxidative damage reducing oxygen consumption, membrane potential, and superoxide anion production," Journal of Pineal Research, vol. 46, no. 2, pp. 188-198, 2009.

[19] D. A. Castroviejo, L. C. López, G. Escames, A. López, J. A. García, and R. J. Reiter, "Melatonin-mitochondria interplay in health and disease," Current Topics in Medicinal Chemistry, vol. 11, no. 2, pp. 221-240, 2011.

[20] S. Anderson, A. T. Bankier, and B. G. Barrell, "Sequence and organization of the human mitochondrial genome," Nature, vol. 290, no. 5806, pp. 457-465, 1981.

[21] O. G. Berg and C. G. Kurland, "Why mitochondrial genes are most often found in nuclei," Molecular Biology and Evolution, vol. 17, no. 6, pp. 951-961, 2000.

[22] G. Schatz, "Mitochondria: beyond oxidative phosphorylation," Biochimica et Biophysica Acta, vol. 1271, no. 1, pp. 123126, 1995.

[23] G. Lenaz and M. L. Genova, "Structure and organization of mitochondrial respiratory complexes: a new understanding of an old subject," Antioxidants and Redox Signaling, vol. 12, no. 8, pp. 961-1008, 2010.

[24] I. Lee, E. Bender, S. Arnold, and B. Kadenbach, "New control of mitochondrial membrane potential and ROS formationa hypothesis," Biological Chemistry, vol. 382, no. 12, pp. 1629-1636, 2001.

[25] M. L. Genova, B. Ventura, G. Giuliano et al., "The site of production of superoxide radical in mitochondrial Complex I is not a bound ubisemiquinone but presumably iron-sulfur cluster N2," FEBS Letters, vol. 505, no. 3, pp. 364-368, 2001.

[26] P. Ghafourifar and C. Richter, "Nitric oxide synthase activity in mitochondria," FEBS Letters, vol. 418, no. 3, pp. 291-296, 1997.

[27] P. Mander and G. C. Brown, "Nitric oxide, hypoxia and brain inflammation," Biochemical Society Transactions, vol. 32, no. 6, pp. 1068-1069, 2004.

[28] E. Esposito and S. Cuzzocrea, "Antiinflammatory activity of melatonin in central nervous system," Current Neuropharmacology, vol. 8, no. 3, pp. 228-242, 2010.

[29] J. Murray, S. W. Taylor, B. Zhang, S. S. Ghosh, and R. A. Capaldi, "Oxidative damage to mitochondrial complex I due to peroxynitrite: identification of reactive tyrosines by mass spectrometry," Journal of Biological Chemistry, vol. 278, no. 39, pp. 37223-37230, 2003.

[30] H. Rubbo, R. Radi, M. Trujillo et al., "Nitric oxide regulation of superoxide and peroxynitrite-dependent lipid peroxidation. Formation of novel nitrogen-containing oxidized lipid derivatives," Journal of Biological Chemistry, vol. 269, no. 42, pp. 26066-26075, 1994. 
[31] E. R. Stadtman and R. L. Levine, "Free radical-mediated oxidation of free amino acids and amino acid residues in proteins," Amino Acids, vol. 25, no. 3-4, pp. 207-218, 2003.

[32] R. L. Levine and E. R. Stadtman, "Oxidative modification of proteins during aging," Experimental Gerontology, vol. 36, no. 9, pp. 1495-1502, 2001.

[33] J. S. Kim, L. He, and J. J. Lemasters, "Mitochondrial permeability transition: a common pathway to necrosis and apoptosis," Biochemical and Biophysical Research Communications, vol. 304, no. 3, pp. 463-470, 2003.

[34] G. Szalai, R. Krishnamurthy, and G. Hajnóczky, "Apoptosis driven by IP-linked mitochondrial calcium signals," EMBO Journal, vol. 18, no. 22, pp. 6349-6361, 1999.

[35] J. J. Lemasters, T. P. Theruvath, Z. Zhong, and A. L. Nieminen, "Mitochondrial calcium and the permeability transition in cell death," Biochimica et Biophysica Acta, vol. 1787, no. 11, pp. 1395-1401, 2009.

[36] D. G. Nicholls and S. L. Budd, "Mitochondria and neuronal survival," Physiological Reviews, vol. 80, no. 1, pp. 315-360, 2000.

[37] W. Dröge, "Free radicals in the physiological control of cell function," Physiological Reviews, vol. 82, no. 1, pp. 47-95, 2002.

[38] S. I. Liochev and I. Fridovich, "Mechanism of the peroxidase activity of $\mathrm{Cu}, \mathrm{Zn}$ superoxide dismutase," Free Radical Biology and Medicine, vol. 48, no. 12, pp. 1565-1569, 2010.

[39] B. Chance, H. Sies, and A. Boveris, "Hydroperoxide metabolism in mammalian organs," Physiological Reviews, vol. 59, no. 3, pp. 527-605, 1979.

[40] Y. Urata, S. Honma, S. Goto et al., "Melatonin induces $\gamma$ glutamylcysteine synthetase mediated by activator protein-1 in human vascular endothelial cells," Free Radical Biology and Medicine, vol. 27, no. 7-8, pp. 838-847, 1999.

[41] I. Antolín, C. Rodriguez, R. M. Sáinz et al., "Neurohormone melatonin prevents cell damage: effect on gene expression for antioxidant enzymes," FASEB Journal, vol. 10, no. 8, pp. 882890, 1996.

[42] M. I. Pablos, R. J. Reiter, G. G. Ortiz et al., "Rhythms of glutathione peroxidase and glutathione reductase in brain of chick and their inhibition by light," Neurochemistry International, vol. 32, no. 1, pp. 69-75, 1998.

[43] R. J. Reiter, D. X. Tan, C. Osuna, and E. Gitto, "Actions of melatonin in the reduction of oxidative stress: a review," Journal of Biomedical Science, vol. 7, no. 6, pp. 444-458, 2000.

[44] C. Rodriguez, J. C. Mayo, R. M. Sainz et al., "Regulation of antioxidant enzymes: a significant role for melatonin," Journal of Pineal Research, vol. 36, no. 1, pp. 1-9, 2004.

[45] V. Jiménez-Ortega, P. Cano, D. P. Cardinali, and A. I. Esquifino, "24-hour variation in gene expression of redox pathway enzymes in rat hypothalamus: effect of melatonin treatment," Redox Report, vol. 14, no. 3, pp. 132-138, 2009.

[46] M. Hara, M. Yoshida, H. Nishijima et al., "Melatonin, a pineal secretory product with antioxidant properties, protects against cisplatin-induced nephrotoxicity in rats," Journal of Pineal Research, vol. 30, no. 3, pp. 129-138, 2001.

[47] G. Escames, A. López, J. A. García et al., "The role of mitochondria in brain aging and the effects of melatonin," Current Neuropharmacology, vol. 8, no. 3, pp. 182-193, 2010.

[48] A. B. Lerner, J. D. Case, Y. Takahashi, T. H. Lee, and W. Mori, "Isolation of melatonin, the pineal gland factor that lightens melanocytes," Journal of the American Chemical Society, vol. 80 , no. 10 , p. $2587,1958$.
[49] A. Carrillo-Vico, J. R. Calvo, P. Abreu et al., "Evidence of melatonin synthesis by human lymphocytes and its physiological significance: possible role as intracrine, autocrine, and/or paracrine substance," The FASEB Journal, vol. 18, no. 3, pp. 537-539, 2004.

[50] A. Slominski, T. W. Fischer, M. A. Zmijewski et al., "On the role of melatonin in skin physiology and pathology," Endocrine, vol. 27, no. 2, pp. 137-147, 2005.

[51] G. A. Bubenik, "Gastrointestinal melatonin: localization, function, and clinical relevance," Digestive Diseases and Sciences, vol. 47, no. 10, pp. 2336-2348, 2002.

[52] S. Jimenez-Jorge, A. J. Jimenez-Caliani, J. M. Guerrero et al., "Melatonin synthesis and melatonin-membrane receptor (MT1) expression during rat thymus development: role of the pineal gland," Journal of Pineal Research, vol. 39, no. 1, pp. 77-83, 2005.

[53] R. E. Rosenstein, S. R. Pandi-Perumal, V. Srinivasan, D. W. Spence, G. M. Brown, and D. P. Cardinali, "Melatonin as a therapeutic tool in ophthalmology: implications for glaucoma and uveitis," Journal of Pineal Research, vol. 49, no. 1, pp. 1-13, 2010.

[54] A. Conti, S. Conconi, E. Hertens, K. Skwarlo-Sonta, M. Markowska, and G. J. M. Maestroni, "Evidence for melatonin synthesis in mouse and human bone marrow cells," Journal of Pineal Research, vol. 28, no. 4, pp. 193-202, 2000.

[55] T. Liu and J. Borjigin, "N-acetyltransferase is not the ratelimiting enzyme of melatonin synthesis at night," Journal of Pineal Research, vol. 39, no. 1, pp. 91-96, 2005.

[56] K. Ackermann and J. H. Stehle, "Melatonin synthesis in the human pineal gland: advantages, implications, and difficulties," Chronobiology International, vol. 23, no. 1-2, pp. 369379, 2006.

[57] H. Tricoire, M. Møller, P. Chemineau, and B. Malpaux, "Origin of cerebrospinal fluid melatonin and possible function in the integration of photoperiod," Reproduction Supplement, vol. 61, pp. 311-321, 2003.

[58] J. Leston, C. Harthé, J. Brun et al., "Melatonin is released in the third ventricle in humans. A study in movement disorders," Neuroscience Letters, vol. 469, no. 3, pp. 294-297, 2010.

[59] D.-X. Tan, L. C. Manchester, E. Sanchez-Barcelo, M. D. Mediavilla, and R. J. Reiter, "Significance of high levels of endogenous melatonin in mammalian cerebrospinal fluid and in the central nervous system," Current Neuropharmacology, vol. 8, no. 3, pp. 162-167, 2010.

[60] D. P. Cardinali, H. J. Lynch, and R. J. Wurtman, "Binding of melatonin to human and rat plasma proteins," Endocrinology, vol. 91, no. 5, pp. 1213-1218, 1972.

[61] E. Gilad and N. Zisapel, "High-affinity binding of melatonin to hemoglobin," Biochemical and Molecular Medicine, vol. 56, no. 2, pp. 115-120, 1995.

[62] D. X. Tan, L. C. Manchester, R. J. Reiter et al., "A novel melatonin metabolite, cyclic 3-hydroxymelatonin: a biomarker of in vivo hydroxyl radical generation," Biochemical and Biophysical Research Communications, vol. 253, no. 3, pp. 614-620, 1998.

[63] F. Hirata, O. Hayaishi, T. Tokuyama, and S. Senoh, "In vitro and in vitro formation of two new metabolites of melatonin," Journal of Biological Chemistry, vol. 249, no. 4, pp. 13111313, 1974.

[64] D. X. Tan, L. C. Manchester, S. Burkhardt et al., " $N^{1}-$ acetyl- $N^{2}$-formyl-5-methoxykynuramine, a biogenic amine 
and melatonin metabolite, functions as a potent antioxidant," The FASEB Journal, vol. 15, no. 12, pp. 2294-2296, 2001.

[65] R. Hardeland, D. X. Tan, and R. J. Reiter, "Kynuramines, metabolites of melatonin and other indoles: the resurrection of an almost forgotten class of biogenic amines," Journal of Pineal Research, vol. 47, no. 2, pp. 109-126, 2009.

[66] R. J. Reiter, "The pineal and its hormones in the control of reproduction in mammals," Endocrine Reviews, vol. 1, no. 2, pp. 109-131, 1980.

[67] V. Srinivasan, W. D. Spence, S. R. Pandi-Perumal, R. Zakharia, K. P. Bhatnagar, and A. Brzezinski, "Melatonin and human reproduction: shedding light on the darkness hormone," Gynecological Endocrinology, vol. 25, no. 12, pp. 779$785,2009$.

[68] R. J. Wurtman and I. Zhdanova, "Improvement of sleep quality by melatonin," Lancet, vol. 346, no. 8988, p. 1491, 1995.

[69] J. M. Guerrero and R. J. Reiter, "Melatonin-immune system relationships," Current topics in medicinal chemistry, vol. 2, no. 2, pp. 167-179, 2002.

[70] V. Srinivasan, G. J. M. Maestroni, D. P. Cardinali, A. I. Esquifino, S. R. Pandi Perumal, and S. C. Miller, "Melatonin, immune function and aging," Immunity and Ageing, vol. 2, article no. 17, 2005.

[71] S. M. Armstrong, "Melatonin and circadian control in mammals," Experientia, vol. 45, no. 10, pp. 932-938, 1989.

[72] S. Deacon and J. Arendt, "Melatonin-induced temperature suppression and its acute phase-shifting effects correlate in a dose-dependent manner in humans," Brain Research, vol. 688, no. 1-2, pp. 77-85, 1995.

[73] S. M. W. Rajaratnam, B. Middleton, B. M. Stone, J. Arendt, and D. J. Dijk, "Melatonin advances the circadian timing of EEG sleep and directly facilitates sleep without altering its duration in extended sleep opportunities in humans," Journal of Physiology, vol. 561, no. 1, pp. 339-351, 2004.

[74] J. Arendt and D. J. Skene, "Melatonin as a chronobiotic," Sleep Medicine Reviews, vol. 9, no. 1, pp. 25-39, 2005.

[75] D. E. Blask, R. T. Dauchy, and L. A. Sauer, "Putting cancer to sleep at night: the neuroendocrine/circadian melatonin signal," Endocrine, vol. 27, no. 2, pp. 179-188, 2005.

[76] V. Srinivasan, D. W. Spence, S. R. Pandi-Perumal, I. Trakht, and D. P. Cardinali, "Therapeutic actions of melatonin in cancer: possible mechanisms," Integrative Cancer Therapies, vol. 7, no. 3, pp. 189-203, 2008.

[77] V. Srinivasan, S. R. Pandi-Perumal, D. W. Spence et al., "Potential use of melatonergic drugs in analgesia: mechanisms of action," Brain Research Bulletin, vol. 81, no. 4-5, pp. 362-371, 2010.

[78] D. P. Cardinali, A. M. Furio, M. P. Reyes, and L. I. Brusco, "The use of chronobiotics in the resynchronization of the sleep-wake cycle," Cancer Causes and Control, vol. 17, no. 4, pp. 601-609, 2006.

[79] D. Dawson and S. M. Armstrong, "Chronobiotics—drugs that shift rhythms," Pharmacology and Therapeutics, vol. 69, no. 1, pp. 15-36, 1996.

[80] P. Pévet, B. Bothorel, H. Slotten, and M. Saboureau, "The chronobiotic properties of melatonin," Cell and Tissue Research, vol. 309, no. 1, pp. 183-191, 2002.

[81] S. M. Reppert, D. R. Weaver, and T. Ebisawa, "Cloning and characterization of a mammalian melatonin receptor that mediates reproductive and circadian responses," Neuron, vol. 13, no. 5, pp. 1177-1185, 1994.

[82] S. M. Reppert, C. Godson, C. D. Mahle, D. R. Weaver, S. A. Slaugenhaupt, and J. F. Gusella, "Molecular characterization of a second melatonin receptor expressed in human retina and brain: the Mel1b melatonin receptor," Proceedings of the National Academy of Sciences of the United States of America, vol. 92, no. 19, pp. 8734-8738, 1995.

[83] M. L. Dubocovich, P. Delagrange, D. N. Krause, D. Sugden, D. P. Cardinali, and J. Olcese, "International union of basic and clinical pharmacology. LXXV. Nomenclature, classification, and pharmacology of $\mathrm{G}$ protein-coupled melatonin receptors," Pharmacological Reviews, vol. 62, no. 3, pp. 343380, 2010.

[84] O. Nosjean, M. Ferro, F. Cogé et al., "Identification of the melatonin-binding site MT as the quinone reductase 2," Journal of Biological Chemistry, vol. 275, no. 40, pp. 3131131317, 2000.

[85] I. Wiesenberg, M. Missbach, J. P. Kahlen, M. Schrader, and C. Carlberg, "Transcriptional activation of the nuclear receptor RZR $\alpha$ by the pineal gland hormone melatonin and identification of CGP 52608 as a synthetic ligand," Nucleic Acids Research, vol. 23, no. 3, pp. 327-333, 1995.

[86] C. Carlberg, "Gene regulation by melatonin," Annals of the New York Academy of Sciences, vol. 917, pp. 387-396, 2000.

[87] C. Tomás-Zapico and A. Coto-Montes, "A proposed mechanism to explain the stimulatory effect of melatonin on antioxidative enzymes," Journal of Pineal Research, vol. 39, no. 2, pp. 99-104, 2005.

[88] A. Menendez-Pelaez, B. Poeggeler, R. J. Reiter, L. BarlowWalden, M. I. Pablos, and D. X. Tan, "Nuclear localization of melatonin in different mammalian tissues: immunocytochemical and radioimmunoassay evidence," Journal of Cellular Biochemistry, vol. 53, no. 4, pp. 373-382, 1993.

[89] D. X. Tan, B. Poeggeler, R. J. Reiter et al., "The pineal hormone melatonin inhibits DNA-adduct formation induced by the chemical carcinogen safrole in vivo," Cancer Letters, vol. 70, no. 1-2, pp. 65-71, 1993.

[90] R. Hardeland, R. J. Reiter, B. Poeggeler, and D. X. Tan, “The significance of the metabolism of the neurohormone melatonin: antioxidative protection and formation of bioactive substances," Neuroscience and Biobehavioral Reviews, vol. 17, no. 3, pp. 347-357, 1993.

[91] B. Poeggeler, S. Thuermann, A. Dose, M. Schoenke, S. Burkhardt, and R. Hardeland, "Melatonin's unique radical scavenging properties-roles of its functional substituents as revealed by a comparison with its structural analogs," Journal of Pineal Research, vol. 33, no. 1, pp. 20-30, 2002.

[92] R. Hardeland, B. Poeggeler, R. Niebergall, and V. Zelosko, "Oxidation of melatonin by carbonate radicals and chemiluminescence emitted during pyrrole ring cleavage," Journal of Pineal Research, vol. 34, no. 1, pp. 17-25, 2003.

[93] R. Hardeland and A. Coto-Montes, "New vistas on oxidative damage and aging," The Open Biology Journal, vol. 3, pp. 3952, 2010.

[94] J. Rosen, NI. N. Than, D. Koch, B. Poeggeler, H. Laatsch, and R. Hardeland, "Interactions of melatonin and its metabolites with the ABTS cation radical: extension of the radical scavenger cascade and formation of a novel class of oxidation products, C2-substituted 3-indolinones," Journal of Pineal Research, vol. 41, no. 4, pp. 374-381, 2006.

[95] D. Tan, R. J. Reiter, L. Chen, B. Poeggeler, L. C. Manchester, and L. R. Barlow-Walden, "Both physiological and pharmacological levels of melatonin reduce DNA adduct formation induced by the carcinogen safrole," Carcinogenesis, vol. 15, no. 2, pp. 215-218, 1994. 
[96] R. J. Reiter, D. X. Tan, J. C. Mayo, R. M. Sainz, J. Leon, and Z. Czarnocki, "Melatonin as an antioxidant: biochemical mechanisms and pathophysiological implications in humans," Acta Biochimica Polonica, vol. 50, no. 4, pp. 1129-1146, 2003.

[97] R. Hardeland and B. Poeggeler, "Melatonin beyond its classical functions," The Open Physiology Journal, vol. 1, pp. $1-23,2008$.

[98] R. Hardeland, A. Coto-Montes, and B. Poeggeler, "Circadian rhythms, oxidative stress, and antioxidative defense mechanisms," Chronobiology International, vol. 20, no. 6, pp. 921962, 2003.

[99] R. Hardeland, "Antioxidative protection by melatonin: multiplicity of mechanisms from radical detoxification to radical avoidance," Endocrine, vol. 27, no. 2, pp. 119-130, 2005.

[100] R. Hardeland, "Melatonin: signaling mechanisms of a pleiotropic agent," BioFactors, vol. 35, no. 2, pp. 183-192, 2009.

[101] J. R. Collins-Underwood, W. Zhao, J. G. Sharpe, and M. E. Robbins, "NADPH oxidase mediates radiation-induced oxidative stress in rat brain microvascular endothelial cells," Free Radical Biology and Medicine, vol. 45, no. 6, pp. 929-938, 2008.

[102] S. K. McCann, G. J. Dusting, and C. L. Roulston, "Early increase of Nox4 NADPH oxidase and superoxide generation following endothelin-1-induced stroke in conscious rats," Journal of Neuroscience Research, vol. 86, no. 11, pp. 25242534, 2008.

[103] C. L. Chen, J. Chen, S. Rawale et al., "Protein tyrosine nitration of the flavin subunit is associated with oxidative modification of mitochondrial complex II in the postischemic myocardium," Journal of Biological Chemistry, vol. 283, no. 41, pp. 27991-28003, 2008.

[104] S. Schiavone, S. Sorce, M. Dubois-Dauphin et al., "Involvement of NOX2 in the development of behavioral and pathologic alterations in isolated rats," Biological Psychiatry, vol. 66, no. 4, pp. 384-392, 2009.

[105] J. Zhou, S. Zhang, X. Zhao, and T. Wei, "Melatonin impairs $\mathrm{NADPH}$ oxidase assembly and decreases superoxide anion production in microglia exposed to amyloid- $\beta$," Journal of Pineal Research, vol. 45, no. 2, pp. 157-165, 2008.

[106] H. Aoshima, K. Kadoya, H. Taniguchi, T. Satoh, and H. Hatanaka, "Generation of free radicals during the death of Saccharomyces cerevisiae caused by lipid hydroperoxide," Bioscience, Biotechnology and Biochemistry, vol. 63, no. 6, pp. 1025-1031, 1999.

[107] Y. Okatani, A. Wakatsuki, R. J. Reiter, and Y. Miyahara, "Acutely administered melatonin restores hepatic mitochondrial physiology in old mice," International Journal of Biochemistry and Cell Biology, vol. 35, no. 3, pp. 367-375, 2003.

[108] C. F. Reyes-Toso, I. R. Rebagliati, C. R. Ricci et al., "Effect of melatonin treatment on oxygen consumption by rat liver mitochondria," Amino Acids, vol. 31, no. 3, pp. 299-302, 2006.

[109] Y. Hibaoui, E. Roulet, and U. T. Ruegg, "Melatonin prevents oxidative stress-mediated mitochondrial permeability transition and death in skeletal muscle cells," Journal of Pineal Research, vol. 47, no. 3, pp. 238-252, 2009.

[110] G. Paradies, G. Petrosillo, V. Paradies, R. J. Reiter, and F. M. Ruggiero, "Melatonin, cardiolipin and mitochondrial bioenergetics in health and disease," Journal of Pineal Research, vol. 48, no. 4, pp. 297-310, 2010.
[111] G. Petrosillo, P. Fattoretti, M. Matera, F. M. Ruggiero, C. Bertoni-Freddari, and G. Paradies, "Melatonin prevents agerelated mitochondrial dysfunction in rat brain via cardiolipin protection," Rejuvenation Research, vol. 11, no. 5, pp. 935943, 2008.

[112] A. W. Linnane, S. Marzuki, T. Ozawa, and M. Tanaka, "Mitochondrial DNA mutations as an important contributor to ageing and degenerative diseases," Lancet, vol. 1, no. 8639, pp. 642-645, 1989.

[113] T. C. Yen, Y. S. Chen, K. L. King, S. H. Yeh, and Y. H. Wei, "Liver mitochondrial respiratory functions decline with age," Biochemical and Biophysical Research Communications, vol. 165, no. 3, pp. 994-1003, 1989.

[114] J. M. Cooper, V. M. Mann, and A. H. V. Schapira, "Analyses of mitochondrial respiratory chain function and mitochondrial DNA deletion in human skeletal muscle: effect of ageing," Journal of the Neurological Sciences, vol. 113, no. 1, pp. 9198, 1992.

[115] Y. H. Wei, S. B. Wu, Y. S. Ma, and H. C. Lee, "Respiratory function decline and DNA mutation in mitochondria, oxidative stress and altered gene expression during aging," Chang Gung Medical Journal, vol. 32, no. 2, pp. 113-132, 2009.

[116] R. S. Sohal and B. H. Sohal, "Hydrogen peroxide release by mitochondria increases during aging," Mechanisms of Ageing and Development, vol. 57, no. 2, pp. 187-202, 1991.

[117] R. Perez-Campo, M. López-Torres, S. Cadenas, C. Rojas, and G. Barja, "The rate of free radical production as a determinant of the rate of aging: Evidence from the comparative approach," Journal of Comparative Physiology B, vol. 168, no. 3, pp. 149-158, 1998.

[118] V. Pesce, A. Cormio, F. Fracasso et al., "Age-related mitochondrial genotypic and phenotypic alterations in human skeletal muscle," Free Radical Biology and Medicine, vol. 30, no. 11, pp. 1223-1233, 2001.

[119] M. Mather and H. Rottenberg, "Aging enhances the activation of the permeability transition pore in mitochondria," Biochemical and Biophysical Research Communications, vol. 273, no. 2, pp. 603-608, 2000.

[120] T. Takeda, "Senescence-accelerated mouse (SAM): a biogerontological resource in aging research," Neurobiology of Aging, vol. 20, no. 2, pp. 105-110, 1999.

[121] M. Hosokawa, "A higher oxidative status accelerates senescence and aggravates age-dependent disorders in SAMP strains of mice," Mechanisms of Ageing and Development, vol. 123, no. 12, pp. 1553-1561, 2002.

[122] Y. Okatani, A. Wakatsuki, R. J. Reiter, and Y. Miyahara, "Hepatic mitochondrial dysfunction in senescence-accelerated mice: correction by long-term, orally administered physiological levels of melatonin," Journal of Pineal Research, vol. 33, no. 3, pp. 127-133, 2002.

[123] Y. Okatani, A. Wakatsuki, and R. J. Reiter, "Melatonin protects hepatic mitochondrial respiratory chain activity in senescence-accelerated mice," Journal of Pineal Research, vol. 32, no. 3, pp. 143-148, 2002.

[124] Y. Okatani, A. Wakatsuki, R. J. Reiter, and Y. Miyahara, "Melatonin reduces oxidative damage of neural lipids and proteins in senescence-accelerated mouse," Neurobiology of Aging, vol. 23, no. 4, pp. 639-644, 2002.

[125] I. Rebrin, S. Zicker, K. J. Wedekind, I. Paetau-Robinson, L. Packer, and R. S. Sohal, "Effect of antioxidant-enriched diets on glutathione redox status in tissue homogenates and mitochondria of the senescence-accelerated mouse," Free 
Radical Biology and Medicine, vol. 39, no. 4, pp. 549-557, 2005.

[126] M. I. Rodriguez, G. Escames, L. C. López et al., "Melatonin administration prevents cardiac and diaphragmatic mitochondrial oxidative damage in senescence-accelerated mice," Journal of Endocrinology, vol. 194, no. 3, pp. 637-643, 2007.

[127] M. I. Rodríguez, G. Escames, L. C. López et al., "Improved mitochondrial function and increased life span after chronic melatonin treatment in senescent prone mice," Experimental Gerontology, vol. 43, no. 8, pp. 749-756, 2008.

[128] A. Navarro and A. Boveris, "Brain mitochondrial dysfunction in aging, neurodegeneration, and Parkinson's disease," Frontiers in Aging Neuroscience, vol. 2, article 34, 2010.

[129] M. Carretero, G. Escames, L. C. López et al., "Long-term melatonin administration protects brain mitochondria from aging," Journal of Pineal Research, vol. 47, no. 2, pp. 192-200, 2009.

[130] A. Navarro and A. Boveris, "The mitochondrial energy transduction system and the aging process," American Journal of Physiology, vol. 292, no. 2, pp. C670-C686, 2007.

[131] E. Fosslien, "Mitochondrial medicine-molecular pathology of defective oxidative phosphorylation," Annals of Clinical and Laboratory Science, vol. 31, no. 1, pp. 25-67, 2001.

[132] D. Mukherjee, S. G. Roy, A. Bandyopadhyay et al., "Melatonin protects against isoproterenol-induced myocardial injury in the rat: antioxidative mechanisms," Journal of Pineal Research, vol. 48, no. 3, pp. 251-262, 2010.

[133] R. J. Reiter, D. X. Tan, L. Fuentes-Broto et al., "Melatonin salvages neural tissue from ischemia/reperfusion injury," The Open Neuroendocrinology Journal, vol. 3, pp. 112-120, 2010.

[134] G. Ambrosio, J. L. Zweier, and J. T. Flaherty, "The relationship between oxygen radical generation and impairment of myocardial energy metabolism following post-ischemic reperfusion," Journal of Molecular and Cellular Cardiology, vol. 23, no. 12, pp. 1359-1374, 1991.

[135] T. L. Vanden Hoek, Z. Shao, C. Li, R. Zak, P. T. Schumacker, and L. B. Becker, "Reperfusion injury in cardiac myocytes after simulated ischemia," American Journal of Physiology, vol. 270, no. 4, pp. H1334-H1341, 1996.

[136] A. P. Halestrap and P. Pasdois, "The role of the mitochondrial permeability transition pore in heart disease," Biochimica et Biophysica Acta, vol. 1787, no. 11, pp. 1402-1415, 2009.

[137] D. X. Tan, L. C. Manchester, R. J. Reiter, W. Qi, S. J. Kim, and G. H. El-Sokkary, "Ischemia/reperfusion-induced arrhythmias in the isolated rat heart: prevention by melatonin," Journal of Pineal Research, vol. 25, no. 3, pp. 184-191, 1998.

[138] S. Kaneko, K. Okumura, Y. Numaguchi et al., "Melatonin scavenges hydroxyl radical and protects isolated rat hearts from ischemic reperfusion injury," Life Sciences, vol. 67, no. 2, pp. 101-112, 2000.

[139] R. Salie, I. Harper, C. Cillie et al., "Melatonin protects against ischaemic-reperfusion myocardial damage," Journal of Molecular and Cellular Cardiology, vol. 33, no. 2, pp. 343$357,2001$.

[140] S. A. Andrabi, I. Sayeed, D. Siemen, G. Wolf, and T. F. Horn, "Direct inhibition of the mitochondrial permeability transition pore: a possible mechanism responsible for antiapoptotic effects of melatonin," The FASEB Journal, vol. 18, no. 7, pp. 869-871, 2004.

[141] F. Luchetti, B. Canonico, F. Mannello et al., "Melatonin reduces early changes in intramitochondrial cardiolipin during apoptosis in U937 cell line," Toxicology in Vitro, vol. 21, no. 2, pp. 293-301, 2007.
[142] E. Sahna, H. Parlakpinar, Y. Turkoz, and A. Acet, "Protective effects of melatonin on myocardial ischemia-reperfusion induced infarct size and oxidative changes," Physiological Research, vol. 54, no. 5, pp. 491-495, 2005.

[143] G. Petrosillo, N. Moro, F. M. Ruggiero, and G. Paradies, "Melatonin inhibits cardiolipin peroxidation in mitochondria and prevents the mitochondrial permeability transition and cytochrome c release," Free Radical Biology and Medicine, vol. 47, no. 7, pp. 969-974, 2009.

[144] H. E. Castagnino, N. Lago, J. M. Centrella et al., "Cytoprotection by melatonin and growth hormone in early rat myocardial infarction as revealed by Feulgen DNA staining," Neuroendocrinology Letters, vol. 23, no. 5-6, pp. 391-395, 2002.

[145] D. Brealey, M. Brand, I. Hargreaves et al., "Association between mitochondrial dysfunction and severity and outcome of septic shock," Lancet, vol. 360, no. 9328, pp. 219-223, 2002.

[146] G. Escames, J. León, M. Macías, H. Khaldy, and D. AcuñaCastroviejo, "Melatonin counteracts lipopolysaccharideinduced expression and activity of mitochondrial nitric oxide synthase in rats," The FASEB Journal, vol. 17, no. 8, pp. 932934, 2003.

[147] V. Srinivasan, S. R. Pandi-Perumal, D. W. Spence, H. Kato, and D. P. Cardinali, "Melatonin in septic shock: some recent concepts," Journal of Critical Care, vol. 25, no. 4, pp. 656.e1656.e6, 2010

[148] G. Escames, L. C. López, V. Tapias et al., "Melatonin counteracts inducible mitochondrial nitric oxide synthasedependent mitochondrial dysfunction in skeletal muscle of septic mice," Journal of Pineal Research, vol. 40, no. 1, pp. 7178, 2006.

[149] L. C. López, G. Escames, V. Tapias, P. Utrilla, J. León, and D. Acuña-Castroviejo, "Identification of an inducible nitric oxide synthase in diaphragm mitochondria from septic mice: its relation with mitochondrial dysfunction and prevention by melatonin," International Journal of Biochemistry and Cell Biology, vol. 38, no. 2, pp. 267-278, 2006.

[150] G. E. Gibson, A. Starkov, J. P. Blass, R. R. Ratan, and M. F. Beal, "Cause and consequence: mitochondrial dysfunction initiates and propagates neuronal dysfunction, neuronal death and behavioral abnormalities in age-associated neurodegenerative diseases," Biochimica et Biophysica Acta, vol. 1802, no. 1, pp. 122-134, 2010.

[151] C. W. Olanow, "An introduction to the free radical hypothesis in Parkinson's disease," Annals of Neurology, vol. 32, pp. S2S9, 1992.

[152] S. Fahn and G. Cohen, "The oxidant stress hypothesis in Parkinson's disease: evidence supporting it," Annals of Neurology, vol. 32, no. 6, pp. 804-812, 1992.

[153] N. Hattori, S. Ikebe, M. Tanaka, T. Ozawa, and Y. Mizuno, "Immunohistochemical studies on complexes I, II, III, and IV of mitochondria in Parkinson's disease," Advances in neurology, vol. 60, pp. 292-296, 1993.

[154] M. Gu, A. D. Owen, S. E. K. Toffa et al., "Mitochondrial function, GSH and iron in neurodegeneration and Lewy body diseases," Journal of the Neurological Sciences, vol. 158, no. 1, pp. 24-29, 1998.

[155] A. Schober, "Classic toxin-induced animal models of Parkinson's disease: 6-OHDA and MPTP," Cell and Tissue Research, vol. 318, no. 1, pp. 215-224, 2004.

[156] M. Terzioglu and D. Galter, "Parkinson's disease: genetic versus toxin-induced rodent models," FEBS Journal, vol. 275, no. 7, pp. 1384-1391, 2008. 
[157] S. Przedborski, K. Tieu, C. Perier, and M. Vila, "MPTP as a mitochondrial neurotoxic model of Parkinson's disease," Journal of Bioenergetics and Biomembranes, vol. 36, no. 4, pp. 375-379, 2004.

[158] G. C. Brown and V. Borutaite, "Inhibition of mitochondrial respiratory complex I by nitric oxide, peroxynitrite and Snitrosothiols," Biochimica et Biophysica Acta, vol. 1658, no. 1-2, pp. 44-49, 2004.

[159] S. Muravchick and R. J. Levy, "Clinical implications of mitochondrial dysfunction," Anesthesiology, vol. 105, no. 4, pp. 819-837, 2006.

[160] E. Absi, A. Ayala, A. Machado, and J. Parrado, "Protective effect of melatonin against the 1-methyl-4-phenylpyridinium-induced inhibition of Complex I of the mitochondrial respiratory chain," Journal of Pineal Research, vol. 29, no. 1, pp. 40-47, 2000.

[161] V. Tapias, G. Escames, L. C. López et al., "Melatonin and its brain metabolite $\mathrm{N}$-acetyl-5-methoxykynuramine prevent mitochondrial nitric oxide synthase induction in Parkinsonian mice," Journal of Neuroscience Research, vol. 87, no. 13, pp. 3002-3010, 2009.

[162] G. A. Dowling, J. Mastick, E. Colling, J. H. Carter, C. M. Singer, and M. J. Aminoff, "Melatonin for sleep disturbances in Parkinson's disease," Sleep Medicine, vol. 6, no. 5, pp. 459466, 2005.

[163] C. A. M. Medeiros, P. F. Carvalhedo De Bruin, L. A. Lopes, M. C. Magalhães, M. De Lourdes Seabra, and V. M. Sales De Bruin, "Effect of exogenous melatonin on sleep and motor dysfunction in Parkinson's disease: a randomized, double blind, placebo-controlled study," Journal of Neurology, vol. 254, no. 4, pp. 459-464, 2007.

[164] D. Kunz and F. Bes, "Melatonin effects in a patient with severe REM sleep behavior disorder: case report and theoretical considerations," Neuropsychobiology, vol. 36, no. 4, pp. 211214, 1997.

[165] D. Kunz and F. Bes, "Melatonin as a therapy in REM sleep behavior disorder patients: an open-labeled pilot study on the possible influence of melatonin on REM-sleep regulation," Movement Disorders, vol. 14, no. 3, pp. 507-511, 1999.

[166] N. Takeuchi, N. Uchimura, Y. Hashizume et al., "Melatonin therapy for REM sleep behavior disorder," Psychiatry and Clinical Neurosciences, vol. 55, no. 3, pp. 267-269, 2001.

[167] B. F. Boeve, M. H. Silber, and T. J. Ferman, "Melatonin for treatment of REM sleep behavior disorder in neurologic disorders: results in 14 patients," Sleep Medicine, vol. 4, no. 4, pp. 281-284, 2003.

[168] K. N. Anderson and J. M. Shneerson, "Drug treatment of REM sleep behavior disorder: the use of drug therapies other than clonazepam," Journal of Clinical Sleep Medicine, vol. 5, no. 3, pp. 235-239, 2009.

[169] R. N. Aurora, R. S. Zak, R. K. Maganti et al., "Best practice guide for the treatment of REM sleep behavior disorder (RBD)," Journal of Clinical Sleep Medicine, vol. 6, no. 1, pp. 85-95, 2010.

[170] F. Li, N. Y. Calingasan, F. Yu et al., "Increased plaque burden in brains of APP mutant MnSOD heterozygous knockout mice," Journal of Neurochemistry, vol. 89, no. 5, pp. 13081312, 2004.

[171] S. Melov, P. A. Adlard, K. Morten et al., "Mitochondrial oxidative stress causes hyperphosphorylation of tau," PLoS One, vol. 2, no. 6, article no. e536, 2007.

[172] C. A. Massaad, R. G. Pautler, and E. Klann, "Mitochondrial superoxide: a key player in Alzheimer's disease," Aging, vol. 1, no. 9, pp. 758-761, 2009.
[173] R. X. Santos, S. C. Correia, X. Wang et al., "Alzheimer's disease: diverse aspects of mitochondrial malfunctioning," International Journal of Clinical and Experimental Pathology, vol. 3, no. 6, pp. 570-581, 2010.

[174] A. Atlante, A. Bobba, V. A. Petragallo, and E. Marra, "Alzheimer's proteins, oxidative stress, and mitochondrial dysfunction interplay in a neuronal model of Alzheimer's disease," International Journal of Alzheimer's Disease, vol. 2010, Article ID 621870, 11 pages, 2010.

[175] W. E. Müller, A. Eckert, C. Kurz, G. P. Eckert, and K. Leuner, "Mitochondrial dysfunction: common final pathway in brain aging and Alzheimer's disease-therapeutic aspects," Molecular Neurobiology, vol. 41, no. 2-3, pp. 159-171, 2010.

[176] M. Manczak, P. Mao, M. J. Calkins et al., "Mitochondriatargeted antioxidants protect against amyloid- $\beta$ toxicity in Alzheimer's disease neurons," Journal of Alzheimer's Disease, vol. 20, supplement 2, pp. S609-S631, 2010.

[177] M. F. Galindo, I. Ikuta, X. Zhu, G. Casadesus, and J. Jordán, "Mitochondrial biology in Alzheimer's disease pathogenesis," Journal of Neurochemistry, vol. 114, no. 4, pp. 933-945, 2010.

[178] P. H. Reddy, M. Manczak, P. Mao, M. J. Calkins, A. P. Reddy, and U. Shirendeb, "Amyloid- $\beta$ and mitochondria in aging and Alzheimer's disease: implications for synaptic damage and cognitive decline," Journal of Alzheimer's Disease, vol. 20, supplement 2, pp. S499-S512, 2010.

[179] J. X. Chen and S. S. Yan, "Role of mitochondrial amyloid$\beta$ in Alzheimer's disease," Journal of Alzheimer's Disease, vol. 20, supplement 2, pp. S569-S578, 2010.

[180] M. Mancuso, D. Orsucci, A. LoGerfo, V. Calsolaro, and G. Siciliano, "Clinical features and pathogenesis of Alzheimer's disease: involvement of mitochondria and mitochondrial DNA," Advances in experimental medicine and biology, vol. 685, pp. 34-44, 2010.

[181] D. P. Cardinali, A. M. Furio, and L. I. Brusco, "Clinical aspects of melatonin intervention in Alzheimer's disease progression," Current Neuropharmacology, vol. 8, no. 3, pp. 218-227, 2010.

[182] E. Matsubara, T. Bryant-Thomas, J. P. Quinto et al., "Melatonin increases survival and inhibits oxidative and amyloid pathology in a transgenic model of Alzheimer's disease," Journal of Neurochemistry, vol. 85, no. 5, pp. 1101-1108, 2003.

[183] Z. Feng, Y. Chang, Y. Cheng et al., "Melatonin alleviates behavioral deficits associated with apoptosis and cholinergic system dysfunction in the APP 695 transgenic mouse model of Alzheimer's disease," Journal of Pineal Research, vol. 37, no. 2, pp. 129-136, 2004.

[184] J. M. Olcese, C. Cao, T. Mori et al., "Protection against cognitive deficits and markers of neurodegeneration by longterm oral administration of melatonin in a transgenic model of Alzheimer disease," Journal of Pineal Research, vol. 47, no. 1, pp. 82-96, 2009.

[185] MI. H. Jang, S. B. Jung, M. H. Lee et al., "Melatonin attenuates amyloid beta-induced apoptosis in mouse microglial BV2 cells," Neuroscience Letters, vol. 380, no. 1-2, pp. 26-31, 2005.

[186] C. H. L. Hung, Y. S. Ho, and R. C. C. Chang, "Modulation of mitochondrial calcium as a pharmacological target for Alzheimer's disease," Ageing Research Reviews, vol. 9, no. 4, pp. 447-456, 2010.

[187] W. Dong, F. Huang, W. Fan et al., "Differential effects of melatonin on amyloid- $\beta$ peptide 25 -35-induced mitochondrial dysfunction in hippocampal neurons at different stages 
of culture," Journal of Pineal Research, vol. 48, no. 2, pp. 117125,2010

[188] X. Wang, "The antiapoptotic activity of melatonin in neurodegenerative diseases," CNS Neuroscience and Therapeutics, vol. 15, no. 4, pp. 345-357, 2009.

[189] J. Quinn, D. Kulhanek, J. Nowlin et al., "Chronic melatonin therapy fails to alter amyloid burden or oxidative damage in old Tg2576 mice: implications for clinical trials," Brain Research, vol. 1037, no. 1-2, pp. 209-213, 2005.

[190] S. Gauthier, B. Reisberg, M. Zaudig et al., "Mild cognitive impairment," Lancet, vol. 367, no. 9518, pp. 1262-1270, 2006.

[191] G. Jean-Louis, H. Von Gizycki, and F. Zizi, "Melatonin effects on sleep, mood, and cognition in elderly with mild cognitive impairment," Journal of Pineal Research, vol. 25, no. 3, pp. 177-183, 1998.

[192] J. S. Peck, D. B. LeGoff, I. Ahmed, and D. Goebert, "Cognitive effects of exogenous melatonin administration in elderly persons: a pilot study," American Journal of Geriatric Psychiatry, vol. 12, no. 4, pp. 432-436, 2004.

[193] A. M. Furio, L. I. Brusco, and D. P. Cardinali, "Possible therapeutic value of melatonin in mild cognitive impairment: a retrospective study," Journal of Pineal Research, vol. 43, no. 4, pp. 404-409, 2007.

[194] R. F. Riemersma-van Der Lek, D. F. Swaab, J. Twisk, E. M. Hol, W. J. G. Hoogendijk, and E. J. W. Van Someren, "Effect of bright light and melatonin on cognitive and noncognitive function in elderly residents of group care facilities: a randomized controlled trial," Journal of the American Medical Association, vol. 299, no. 22, pp. 2642-2655, 2008.

[195] I. Túnez, P. Montilla, M. D.C. Muñoz, M. Feijóo, and M. Salcedo, "Protective effect of melatonin on 3-nitropropionic acid-induced oxidative stress in synaptosomes in an animal model of Huntington's disease," Journal of Pineal Research, vol. 37, no. 4, pp. 252-256, 2004.

[196] J. M. A. Oliveira, "Nature and cause of mitochondrial dysfunction in Huntington's disease: focusing on huntingtin and the striatum," Journal of Neurochemistry, vol. 114, no. 1, pp. 1-12, 2010.

[197] V. Heiser, E. Scherzinger, A. Boeddrich et al., "Inhibition of huntingtin fibrillogenesis by specific antibodies and small molecules: Implications for Huntington's disease therapy," Proceedings of the National Academy of Sciences of the United States of America, vol. 97, no. 12, pp. 6739-6744, 2000.

[198] L. Wetterberg, L. Iselius, and J. Lindsten, "Genetic regulation of melatonin excretion in urine. A preliminary report," Clinical Genetics, vol. 24, no. 6, pp. 399-402, 1983.

[199] E. Grof, P. Grof, and G. M. Brown, "Investigations of melatonin secretion in man," Progress in Neuro-Psychopharmacology and Biological Psychiatry, vol. 9, no. 5-6, pp. 609612, 1985.

[200] J. D. Bergiannaki, C. R. Soldatos, T. J. Paparrigopoulos, M. Syrengelas, and C. N. Stefanis, "Low and high melatonin excretors among healthy individuals," Journal of pineal research, vol. 18, no. 3, pp. 159-164, 1995.

[201] B. Griefahn, P. Bröde, T. Remer, and M. Blaszkewicz, "Excretion of 6-hydroxymelatonin sulfate (6-OHMS) in siblings during childhood and adolescence," Neuroendocrinology, vol. 78, no. 5, pp. 241-243, 2003.

[202] P. Gałecki, J. Szemraj, G. Bartosz et al., "Single-nucleotide polymorphisms and mRNA expression for melatonin synthesis rate-limiting enzyme in recurrent depressive disorder," Journal of Pineal Research, vol. 48, no. 4, pp. 311-317, 2010. 


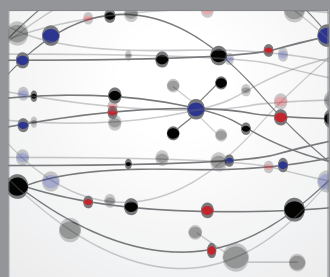

The Scientific World Journal
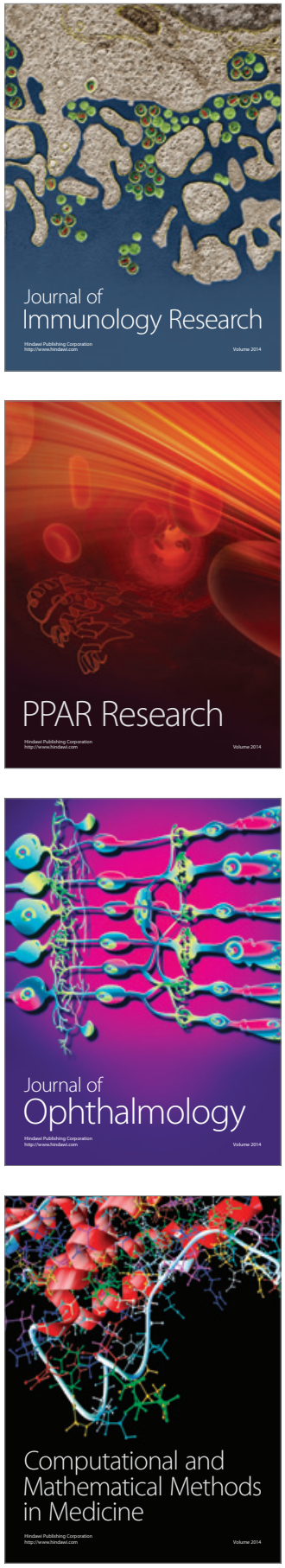

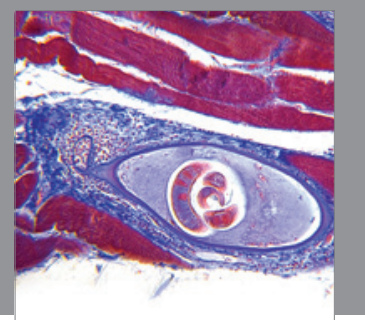

Gastroenterology

Research and Practice
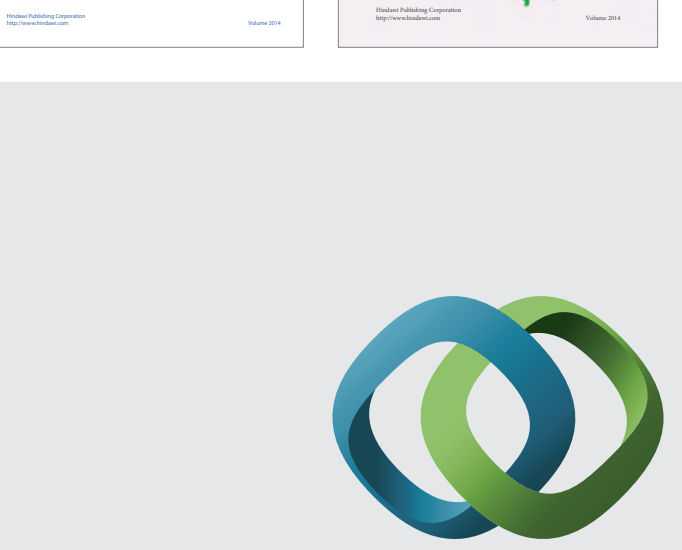

\section{Hindawi}

Submit your manuscripts at

http://www.hindawi.com
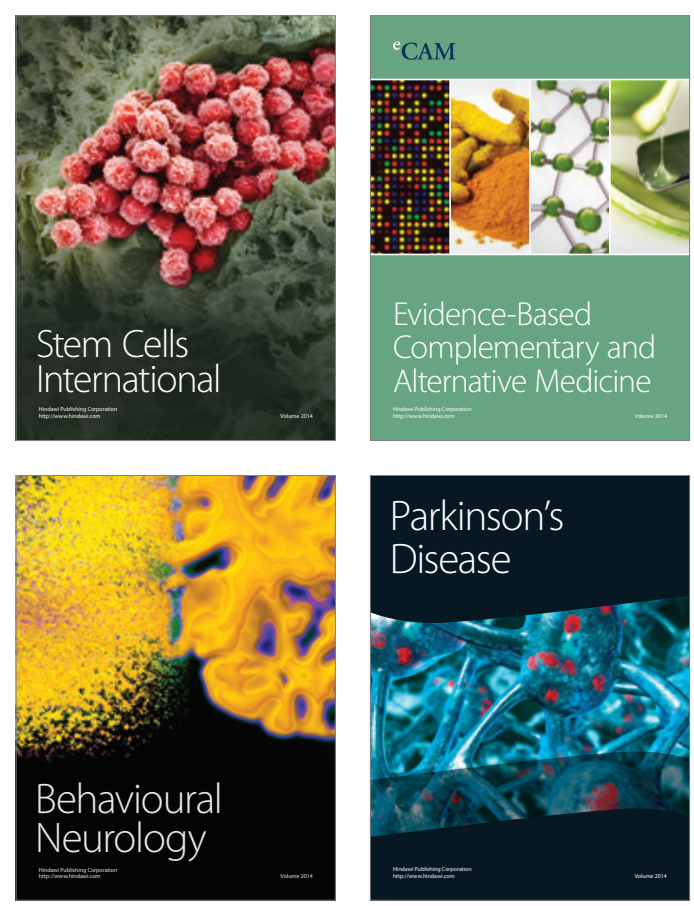

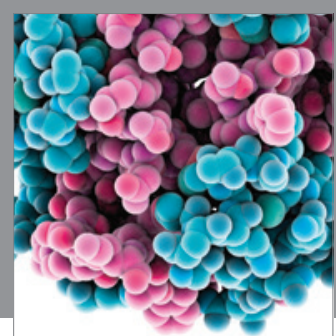

Journal of
Diabetes Research

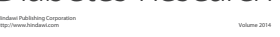

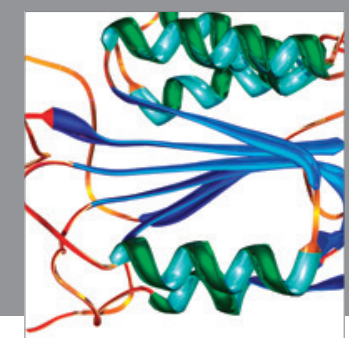

Disease Markers
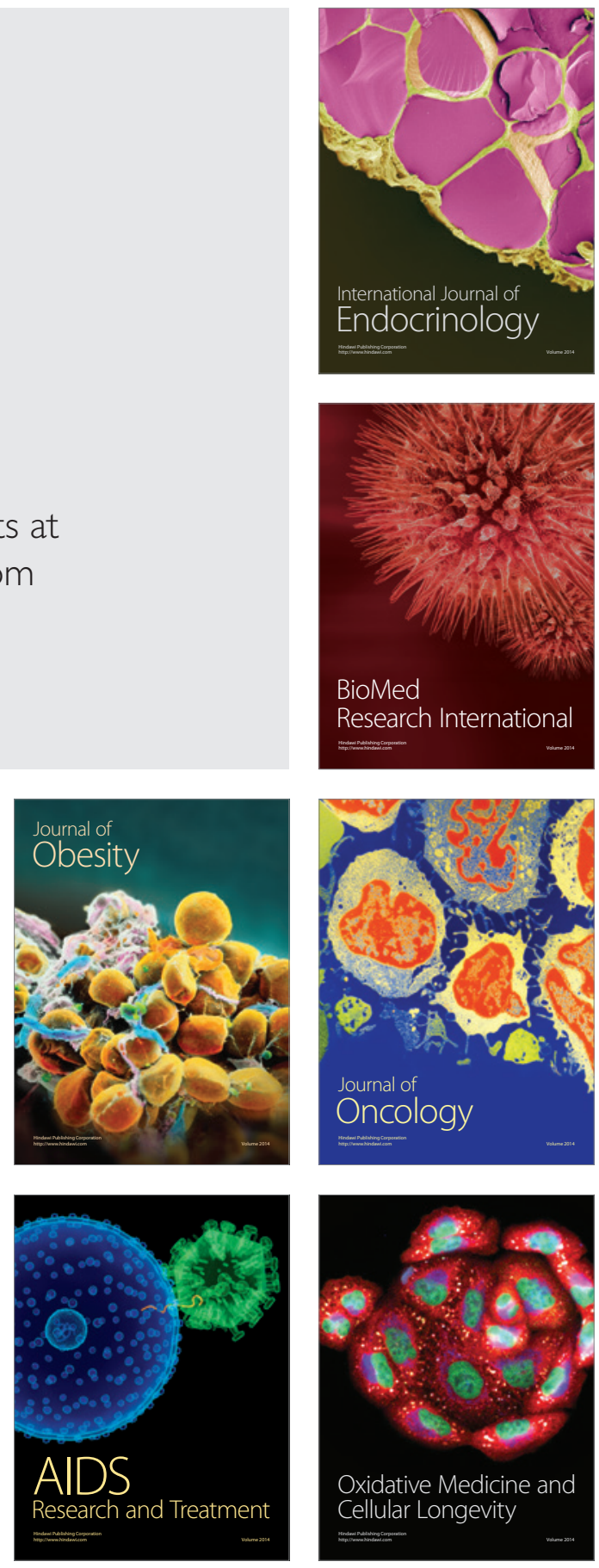